\title{
Factors affecting teachers' level of classroom Internet use and teachers' self -efficacy regarding classroom Internet use
}

\author{
George R. Watson \\ West Virginia University
}

Follow this and additional works at: https://researchrepository.wvu.edu/etd

\footnotetext{
Recommended Citation

Watson, George R., "Factors affecting teachers' level of classroom Internet use and teachers' self -efficacy regarding classroom Internet use" (2006). Graduate Theses, Dissertations, and Problem Reports. 2711. https://researchrepository.wvu.edu/etd/2711

This Dissertation is protected by copyright and/or related rights. It has been brought to you by the The Research Repository @ WVU with permission from the rights-holder(s). You are free to use this Dissertation in any way that is permitted by the copyright and related rights legislation that applies to your use. For other uses you must obtain permission from the rights-holder(s) directly, unless additional rights are indicated by a Creative Commons license in the record and/ or on the work itself. This Dissertation has been accepted for inclusion in WVU Graduate Theses, Dissertations, and Problem Reports collection by an authorized administrator of The Research Repository @ WVU. For more information, please contact researchrepository@mail.wvu.edu.
} 
Factors Affecting Teachers' Level of Classroom Internet Use and Teachers' Self-efficacy Regarding Classroom Internet Use

\author{
George R. Watson
}

Dissertation submitted to the College of Human Resources and Education At West Virginia University in partial fulfillment of the requirements for the degree of

\title{
Doctor of Education in
} Curriculum and Instruction

\author{
Randall Wiesenmayer, Ph.D. Chair \\ John Wells, Ph.D \\ Ronald Iannone, Ph.D. \\ Kenneth Murray, Ph.D. \\ John Oughton, Ph.D.
}

Department of Curriculum and Instruction

Morgantown, West Virginia

2006

Keywords: Classroom Internet, self-efficacy, Internet use, Internet self-efficacy, Classroom Internet Factors

Copyright 2006, George Watson 


\section{ABSTRACT \\ Factors Affecting Teachers' Level of Classroom Internet Use and Teachers' Self-efficacy Regarding Classroom Internet Use}

\section{George R. Watson}

This study examined the factors that affect teacher classroom Internet use and teacher self-efficacy with using the Internet. With regards to classroom Internet use, the factors examined were grade taught, years of teaching experience, type of school technical support, Internet-related professional development training, number of Internet-accessible computers in the classroom, student socioeconomic status, and teacher Internet self-efficacy. For teacher Internet self-efficacy, the factors examined were years of teaching experience, type of school technical support, and Internet-related professional development training. This study surveyed 419 public school teachers, across grades K-12, using stepwise multiple regression to analyze the factors and their relationships with classroom Internet use and teacher Internet self-efficacy.

The results from the 419 survey respondents indicate that grade taught, number of Internet-accessible classroom computers, school socioeconomic status, and teacher Internet selfefficacy were all significant predictors of classroom Internet use. In-service training and multiple-day workshops were also found to be significant predictors of classroom Internet use, but the variable college credit courses was not. Further, the factors of years of teaching experience and type of technical support were not significant predictors. The data for teacher Internet self-efficacy indicated that years of teaching experience was a negative predictor of selfefficacy, while all three types of professional development were a positive predictor. Technical support was not a predictor of teacher Internet self-efficacy. 


\section{ACKNOWLEDGEMENTS}

It is difficult to list all the people who have helped me through this process. Of course, I must start by thanking my advisor, Dr. Wiesenmayer, and my co-chair, Dr. Wells, who both have shown remarkable patience and perseverance with my work, especially being willing to work with me from a distance.

There are several people who also deserve high praise for their help in my completion of this dissertation. First, my parents, who have supported me without fail in all things, without them this would never have been possible. My brothers and sister, who took on the life's mission to keep their little brother out of trouble, and various teachers and professors who have helped me develop as a teacher and person along the way.

Without question, though, this would not have been possible without the love and support of my wife and family. If ever a diploma should have two names, then mine should also include my wife's. The countless hours of time that I was traveling, attending classes, or staring into my laptop mumbling incoherently make this as much her project as mine. My children also supported me by letting me work and providing much needed entertainment breaks when the stress and anxiety became too much. Thank you just does not begin to reflect my appreciation. 


\section{TABLE OF CONTENTS}

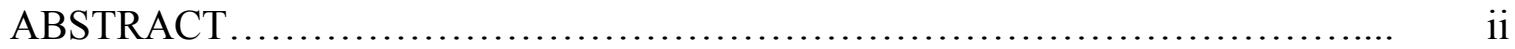

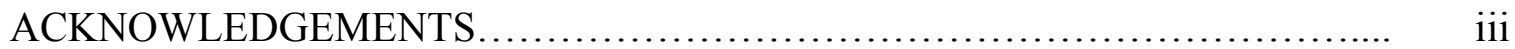

TABLE OF CONTENTS ................................................... iv

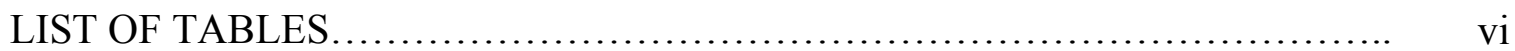

CHAPTER 1 INTRODUCTION.......................................... 1

Statement of the Problem................................................... 1

Purpose of the Study.................................................. 3

Background and Significance......................................... 5

Classroom Internet Use and Research on Factors Affecting It............. 5

Internet Use and Student Grade Level................................ 5

Internet Use and Teaching Experience............................ 5

Internet Use and Technical Support............................... 6

Internet Use and Professional Development......................... 6

Internet Use and Internet-accessible Computers in the Classroom....... 8

Internet Use and Socioeconomic Status of Schools................... 8

Internet Use and Self-efficacy................................... 8

Teacher Self-efficacy with using the Internet.............................. 9

Self-efficacy and Teaching Experience............................. 9

Self-efficacy and Technical Support................................... 9

Self-efficacy and Professional Development......................... 10

Technology Integration.............................................. 11

Research Questions.................................................. 12

Hypotheses....................................................... 12

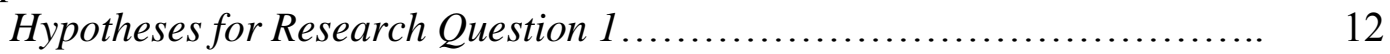

Hypotheses for Research Question 2.................................. 13

Assumptions of the Research.......................................... 14

Limitations of the Study ............................................ 14

Definitions......................................................... 14

CHAPTER 2 REVIEW OF LITERATURE.................................. 17

Classroom Internet Use and Factors Affecting It.......................... 17

Internet Use and Student Grade Level........................................... 17

Internet Use and Teaching Experience........................................ 18

Internet Use and Technical Support.......................................... 18

Internet Use and Professional Development.................................... 19

Internet Use and Internet-accessible Computers in the Classroom............ 22

Internet Use and Socioeconomic Status of Schools............................. 23

Internet Use and Self-efficacy............................................... 26

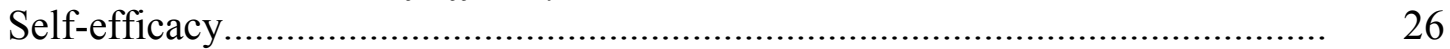

Factors Affecting Teacher Self-efficacy with Computers and the Internet......... 27

Self-efficacy and Teaching Experience.................................. 27

Self-efficacy and Technical Support................................... 28

Self-efficacy and Professional Development.............................. 28

Gender Differences and Internet Use........................................................... 29

Promoting Inquiry-based Learning Through Computer/Internet Use.................. $\quad 30$ 
National Educational Technology Standards (NETS)...................................... 31

Qualitative Versus Quantitative Research........................................................... 33

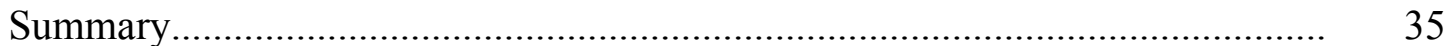

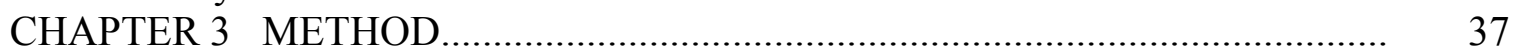

Research Design and Data Analysis.......................................................... $\quad 37$

Independent and Dependent Variables for Research Questions........................ $\quad 38$

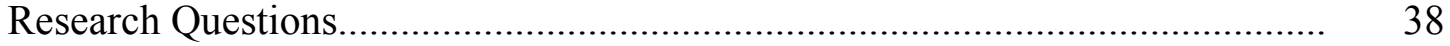

Hypotheses............................................................................................ 40

Hypotheses for Research Question 1..................................................... 40

Hypotheses for Research Question 2..................................................... 41

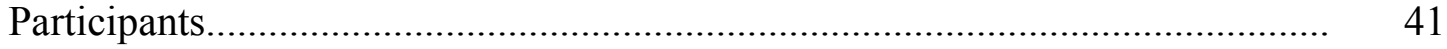

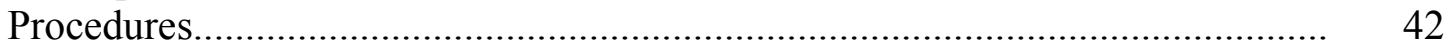

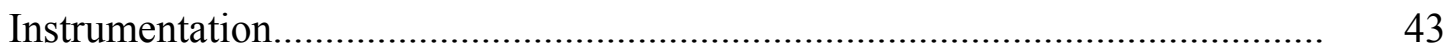

Validity and Reliability of the CIS Instrument............................................. 45

Data Analysis........................................................ 48

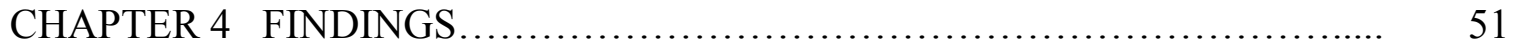

General Teacher and School Characteristics.............................. 52

Findings on Level of Classroom Internet Use............................. 59

Grade Taught and Level of Classroom Internet Use..................... 65

Years of Teaching Experience and Level of Classroom Internet Use........ 65

Technical Support and Level of Classroom Internet Use.............................. 66

Professional Development and Level of Classroom Internet Use............. 67

Number of Internet-accessible Computers and Level of Classroom Internet Use........................................................ 70

School Socioeconomic Status and Level of Classroom Internet Use........... $\quad 70$

Teacher Internet Self-efficacy and Level of Classroom Internet Use......... 71

Summary of Factors Affecting Classroom Level of Internet Use............ 72

Findings on Teacher Internet Self-efficacy.............................. 73

Years of Teaching Experience and Teacher Internet Self-efficacy........... 76

Technical Support and Teacher Internet Self-efficacy................................ $\quad 77$

Professional Development and Teacher Internet Self-efficacy.............. 78

Summary of Factors Affecting Teacher Internet Self-efficacy............... 81

CHAPTER 5 CONCLUSIONS, IMPLICATIONS, and RECOMMENDATIONS 82

Conclusions..................................................... 83

Conclusions for Research Question 1................................. 84

Conclusions for Research Question 2.................................. 86

Implications..................................................... 87

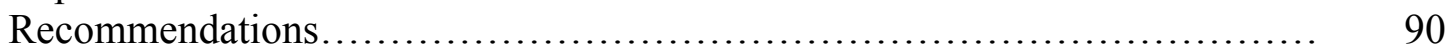

REFERENCES .................................................... 93

Appendix A Classroom Internet Survey (CIS) Instrument....................... 100

Appendix B Calculating LOU and PITEBS Scores........................... 106

Appendix C Content Validity of Survey................................... 108 


\section{List of Tables}

Table 1.1 Dependent and Independent Variables of Study..................... 4

Table 3.1 Dependent and Independent Variables of Study..................... 39

Table 3.2 CIS Instrument Content Validity Scores by Panel Member............... 47

Table 3.3 Research Questions and Related Survey Questions .................... 48

Table 4.1 Response Frequencies for School Socioeconomic Status Across Grades Taught........................................................... 53

Table 4.2 Response Frequencies for Teachers' Years of Experience............... 53

Table 4.3 Response Frequencies for Types of Technical Support................. 54

Table 4.4 Response Frequencies for Number of Classroom Internet-accessible

Computers by Grade Level.......................................... $\quad 55$

Table 4.5 Response Frequencies for Number of Classroom Internet-accessible Computers by Grade Level and SES.................................... 56

Table 4.6 Response Frequencies for Internet Professional Development CE

Credits........................................................ 57

Table 4.7 Response Frequencies for College Credit Hours with Internet

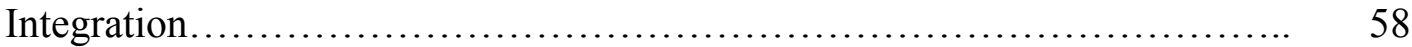

Table 4.8 Response Frequencies for Participation in Multiple-day Workshops..... 58

Table 4.9 Survey Response Frequencies for Level of Classroom Internet Use..... 60

Table 4.10 Summary of Stepwise Regression Analysis of Variables Predicting

Teacher Level of Internet Use in the Classroom.......................... 64

Table 4.11 Mean Level of Use Scores Based on Grade Level Taught............... 65

Table 4.12 Mean Level of Use Scores Based on Years of Teaching Experience...... 66

Table 4.13 Mean Level of Use Scores Based on Type of Technical Support

Received......................................................... 67

Table 4.14 Mean Level of Use Scores Based on CE Credits....................... 68

Table 4.15 Mean Level of Use Scores Based on College Credits Earned............. 69

Table 4.16 Mean Level of Use Scores Based on the Number of Multiple-day

Workshops Attended............................................... 69

Table 4.17 Mean Level of Use Scores Based on Number of Internet-accessible

Computers in the Classroom......................................... $\quad 71$

Table 4.18 Mean Level of Use Scores Based on Teacher Internet Self-efficacy

Score ............................................................ $\quad 72$

Table 4.19 Teacher Responses on Internet Self-efficacy...................... 74

Table 4.20 Summary of Stepwise Regression Analysis of Variables Predicting

Teacher Internet Self-efficacy........................................ 76

Table 4.21 Mean PITEBS Score Based on Years of Teaching Experience........... 77

Table 4.22 Mean PITEBS Score Based on Type of Technical Support.............. 78

Table 4.23 Mean PITEBS Score Based on CE Credits Earned...................... 79

Table 4.24 Mean PITEBS Score Based on College Credits Earned.................. 80

Table 4.25 Mean PITEBS Score Based on Multiple-day Workshops Attended...... 80 


\section{CHAPTER 1}

Introduction

The idea of incorporating computer access and the Internet into the K-12 classroom has been a major focus of education reform over the last several years (President's Committee of Advisors on Science and Technology, 1997; U.S. Department of Education, 2002). As part of this focus, efforts have been made to close the "digital divide", which is a term commonly used to describe the differences in the type, quantity, and quality of computers and Internet access between affluent and poorer schools. The efforts of local, state, federal, and private sector initiatives have significantly lessened the computer and Internet accessibility differences across the divide. Billions of dollars have been spent, with a great deal of success, to bring computers and the Internet into almost every public school classroom in the United States, as now nearly every school classroom has computers connected to the Internet (National Center for Educational Statistics [NCES], 2004a).

Counting the number of computers and type of Internet connections in schools is one way to determine improvement in educational access to the Internet, but another part of this integration process is the competence and comfort level of teachers to use the Internet in their

teaching. Less attention has been paid to the differences in teacher training between affluent and less affluent schools, and the lack of adequate professional development funding for poorer school districts makes the goal of completely closing the digital divide very difficult (Hoover, 2003).

\section{Statement of the Problem}

This study examines teachers' level of Internet use with regards to several demographic factors, as well as the effect of various factors on teachers' self-efficacy with using the Internet. 
Teachers' level of Internet use was examined in terms of the following independent variables: professional development training, years of teaching experience, grade level taught by the teacher, number of Internet-accessible computers in the classroom, student socioeconomic status, self-efficacy with using the Internet, and type of technical support available to the teacher. The second part of the study was to determine the degree that self-efficacy using the Internet is related to: professional development training, years of teaching experience, and type of technical support available to the teacher. From the understanding of these factors relating to level of classroom Internet use and teacher Internet self-efficacy, better methods of training and classroom support for teachers might be created. Also, knowledge of the factors will help administrators better plan and implement Internet integration and use of available Internetrelated resources.

There have been several long-term studies of technology use, proficiency, and feelings of efficacy in regards to computer and Internet use with mixed results. In one, a three-year study of pre-service teachers, it was found that feelings of self-efficacy and computer technology increased significantly between the first and second years, and maintained a high level of efficacy during the third year (Milbraith \& Kinzie, 2000). Another study, conducted by the American Institutes for Research (AIR) for the U.S. Department of Education (1999), examined the Eisenhower Professional Development Program, a federal government program devoted to developing the knowledge and skills of in-service teachers. This study of 30 elementary, middle, and secondary schools, and over 430 teachers during the 1996-97, 1997-98, and 1998-99 school years found little change in overall teaching practice. Their conclusion was that the teachers' inability to develop improved strategies was related to the wide variation in amount and quality of professional development received over the course of the study. 
Many researchers have suggested that there is a link between school environmental factors and Internet use in the classroom. A study conducted by Garland and Wotton (2002) found that school size, school funding, poverty level of students, achievement on state assessments, and teacher training were all indicators of whether schools had significant technology resources and how they used them.

The digital divide between the affluent and poor has been well documented (NCES, 2004b; NTIA, 2002), and there have been several federal programs put in place in an attempt to narrow the gap, such as the Telecommunications Act of 1996, also known as the E-rate, and the Enhancing Education Through Technology Program (Ed Tech) program (U.S. Department of Education, 2002). Nevertheless, the divide in technology use by students at home and school still exists (NCES, 2004b). Some researchers suggest the digital divide is also at least partially based on factors other than poverty. One study, by Mills and Whitacre (2003), found a significant difference in home Internet use between residents of metropolitan areas and nonmetropolitan (rural) areas. The difference was explained in the research by differences in family income and limitations of Internet connectivity option in the non-metropolitan areas.

\section{Purpose of the Study}

The purpose of this study was twofold. One purpose was to determine to what degree a teacher's level of Internet use is related to eight independent variables: grade level taught by the teacher, years of teaching experience, type of technical support available to the teacher, professional development training received by the teacher, number of Internet-accessible computers in the classroom, student population socioeconomic status, and self-efficacy with using the Internet. The second purpose of the study was to determine the degree that selfefficacy with using the Internet is related to these independent variables: years of teaching 
experience, level of technical support available to the teacher, and Internet-related professional development training received by the teacher.

Table 1.1 lists the dependent (DV) and independent (IV) variables for the study.

Table 1.1

Dependent and Independent Variables of Study

Variable Description

DV 1 Teacher's level of classroom Internet use

IV Grade level of students taught by the teacher

IV Years of teaching experience

IV Type of technical support available to the teacher

IV Internet-related professional development training received by the teacher

IV Number of Internet-accessible computers in the classroom

IV Socioeconomic status of the student population

IV Teacher self-efficacy with using the Internet

DV 2 Teacher's level of self-efficacy regarding classroom Internet use

IV Years of teaching experience

IV Type of technical support available to the teacher

IV Internet-related professional development training received by the teacher

The results of this study have implications to classroom Internet integration and the professional development dealing with this integration. The study's findings give indications as to the manner with which technical support, gender, and other variables singly, or in some combination, interact in ways that encourage or prevent Internet integration in the classroom. 
Findings from this study show that certain types of professional development are more effective, therefore improving developers' ability to design better training methods. Also, the research findings indicate what role graduate courses play in predicting the level of Internet use as well as teacher feelings and comfort with using the Internet. This knowledge will be helpful in future training and development activities, as well as more effective methods to implement classroom Internet integration to overcome the digital divide.

\section{Background and Significance}

\section{Classroom Internet Use and Research on Factors Affecting It}

\section{Internet Use and Student Grade Level}

At one time there was a significant difference in the availability and use of the Internet between schools based on student grade level. In 1994, 49\% of secondary schools had Internet access, while only $30 \%$ of elementary schools had access. By 2002 this gap had been all but eliminated, as nearly all elementary and secondary schools had access to the Internet (NCES, 2004a). When examining where the access is in relationship to the classroom, once again there is almost no difference between elementary and secondary schools. In 1994, 3\% of elementary classrooms had Internet access as opposed to $4 \%$ of secondary, but by $2002,92 \%$ of elementary classrooms and 91\% of secondary classrooms were wired (NCES, 2004a).

\section{Internet Use and Teaching Experience}

Teachers' lack of preparedness to use computers and the Internet begins at the pre-service level. An examination of the students entering an education degree program reveals surprising differences between education majors and non-education majors. In a ten-year study of undergraduate students, Reed, Ervin, and Oughton (1995) found that education majors have a higher computer anxiety and less computer experience than students in other majors. Another 
study, by Reehm, Long, and Dickey (2001) found that pre-service teachers score lower on some measures of computer skills and knowledge than their peers. They felt the disparity was caused by the lack of elective computer courses for pre-service teachers and little emphasis on technology in core education courses.

\section{Internet Use and Technical Support}

Teacher use of Internet technology has been found to be directly affected by access to technical support (Norris, Sullivan, Poirot, \& Soloway, 2003), and schools use a variety of ways to provide that support for teachers. Nationwide in $2002,38 \%$ of schools had a full-time school technology person, $26 \%$ had district-level staff that provided support, $18 \%$ designated a teacher as technology support as part of their regular duties, $11 \%$ used a part-time person, and $7 \%$ used outside staff or volunteers (NCES, 2004a). In the study by Norris et al., 3,665 teachers in four states (California, Florida, Nebraska, and New York) were surveyed about their use of computers in the classroom, and respondents came from schools that were both rural and urban. The study results indicated that access to technical assistance was a significant predictor of classroom Internet use. In another study, teachers who had access to assistance were significantly more likely to use classroom time on the Internet with students. In the study, $56 \%$ of the teachers with available assistance used the Internet compared to $42 \%$ of teachers in schools that did not have easy access to support (NCES, 2000b)

\section{Internet Use and Professional Development}

Some studies have shown that teacher training is a significant factor in Internet integration (President's Committee of Advisors on Science and Technology, 1997; Skinner, 2002). The efforts to change the way we teach and use technology and the Internet have increased dramatically over the last few years. These efforts to train teachers come from a 
variety of federal, state, local, and private initiatives. The federal government alone spends billions of dollars every year on efforts to train teachers. While state and local programs vary on their goals and methods, the federal effort to improve student achievement in schools centers on the No Child Left Behind Act of 2001 (NCLB). Title II of the law focuses on improving teacher quality as determined by subject area content knowledge and teaching effectiveness. To accomplish this NCLB created the Improving Teacher Quality State Grants program to allow individual states to fund professional development activities that were research driven, measurable, promoted higher qualifications for teachers, and improved the student achievement. Programs under the NCLB umbrella, including the Improving Teacher Quality State Grants program total almost \$23.7 billion for the 2003 fiscal year (U.S. Department of Education, 2002).

Using technology effectively in the classroom is also a major thrust of NCLB (U.S. Department of Education, October 2004). As part of the reorganization implemented through NCLB, the Enhancing Education Through Technology Program (Ed Tech) was established to provide funds to states to implement and support effective use of technology in schools (U.S. Department of Education, 2002). Part of the guidelines call for $25 \%$ of any grant to go towards teacher professional development, short of the $30 \%$ recommended by the report, "Report to the president on the use of technology to strengthen K-12 education in the United States" (President's Committee of Advisors on Science and Technology, 1997). This is, however, significantly higher than the $14 \%$ typically spent on technology professional development by schools and educational agencies (Skinner, 2002). With a 2003 budget of almost $\$ 700$ million, the need to spend these monies on effective professional development is paramount (U.S. Department of Education, 2002). 


\section{Internet use and Internet-accessible Computers in the Classroom}

In a study by Gibson and Oberg (2004) the researchers found that teachers who had access to the Internet in their classrooms were more likely to use the technology in their teaching than teachers who did not. Another study, by Ravitz (1998) found that a combination of Internet-accessible computers in the classroom and computer labs with 20-30 Internet-connected machines provided the best conditions to facilitate teacher use.

Internet Use and Socioeconomic Status of Schools

One of the major concerns regarding technology and Internet use in schools is the digital divide, the separation in the number and quality of computers and other technology between affluent schools and poorer schools. The National Center for Education Statistics notes that in 2002, schools with the highest number of low-income students had 5.5 students for every Internet-accessible computer, compared to 4.6 per computer in schools that had few low-income students (NCES, 2004a). In addition, the digital divide has also come to describe the differences between children's access to the Internet at home, based on race or family income. In 2001, only $31.2 \%$ of students with a family income of less than $\$ 20,000$ had access to computers at home, while $89.3 \%$ of students in families making over $\$ 75,000$ did (NCES, 2004b).

\section{Internet Use and Self-efficacy}

Self-efficacy may be defined as a belief in one's own ability to perform an action or activity necessary to achieve a goal or task (Bandura, 1997). There have been several long-term studies of technology use, proficiency, and feelings of efficacy in regards to computer and Internet use with mixed results. In a three year study of pre-service teachers, it was found that feelings of self-efficacy and computer technology increased significantly between the first and second year, and maintained a high level of efficacy during the third year (Milbraith and Kinzie, 
2000). Another study, by American Institutes for Research (AIR) for the U.S. Department of Education (1999) examined the Eisenhower Professional Development Program, the federal government program devoted to developing the knowledge and skills of in-service teachers. This study of 30 elementary, middle, and secondary schools, and over 430 teachers during the 1996-97, 1997-98, and 1998-99 school years found little change in overall teaching practice even with professional development. Their conclusion indicated that the teachers' inability to develop improved strategies was related to the wide variation in the amount and quality of professional development received over the course of the study.

Teacher Self-efficacy With Using the Internet Self-efficacy and Teaching Experience

Watson (in press) found that professional development improved long-term Internet selfefficacy. The study examined teacher levels of Internet self-efficacy on 296 in-service teachers that took part in a five-day intensive Internet skills workshop. The data were the result of combining the data from a survey done immediately after the workshop with data taken from the same instrument and the same group of teachers six years later. The results indicated that teacher feelings of anxiety and self-efficacy remained constant over time. Further, teachers in the group who had participated in two workshop-related on-line courses had higher levels of confidence than those that did not. The results were consistent even when controlling for factors such as other technology professional development, college level technology courses, and years of teaching experience.

\section{Self-efficacy and Technical Support}

Perception of barriers to technology and Internet integration may prevent teachers from attempting to use technology in the classroom. The amount and type of technical support 
available may play a role in teacher comfort with technology and therefore its potential for use. In 1999, the NCES completed a survey of teachers nationwide on their use of technology in the classroom; looking at all types of technology usage and the problems teachers reported having with its use. The study surveyed 2,109 teachers, encompassing all 50 states and the District of Columbia, and included elementary, middle, and secondary school teachers. Results of this study found that teachers who did not have an on-site technology support person were two to three times more likely to report that institutional and technical support was a significant obstacle in integrating technology. Specifically, the NCES report found that $39 \%$ of teachers in schools that had no technical support person in the school reported technical support as a significant barrier to integration, compared to $12 \%$ of teachers in schools that did have a technologist on staff (NCES, 2000b).

\section{Self-efficacy and Professional Development}

There have been several long-term studies of technology use, proficiency, and feelings of efficacy in regards to computer and Internet use with mixed results. In a three-year study of preservice teachers, it was found that feelings of self-efficacy and computer technology increased significantly between years one and two, and maintained a high level of efficacy during year three (Milbraith \& Kinzie, 2000). A study of over 430 teachers from 30 elementary, middle, and secondary schools during the 1996-97, 1997-98, and 1998-99 school years looked at the effect that professional development had on changing teacher use of computers and the Internet(U.S. Department of Education, 1999). The study's conclusion indicated that the teachers' inability to develop improved strategies was related to the wide variation in amount and quality of professional development received. 


\section{Technology Integration}

Over the last decade a major emphasis in education has been the integration of the Internet into the classroom. The Internet has been heralded as an agent of transformation in the educational system, a tool that gives students access to wide-ranging resources and information as well as opportunities for collaboration with others without concern for geographical distance. Teachers are not only encouraged to use the Internet as part of instruction but expected to use it to meet educational goals and standards by the third grade (International Society for Technology in Education [ISTE], 2004). The National Educational Technology Standards (NETS), a set of national technology standards created by ISTE, are the basis for most states' efforts to integrate technology in the classroom. As an example of expectations for teachers to use the Internet, by no later than the fifth grade the NETS standards call for student use of the Internet as a research and communication tool in the classroom (ISTE, 2004). Another example of the increased expectations for teachers is that 32 states now have a technology component in their teacher certification process (Thomas, Adams, Meghani, \& Smith, 2002).

As stated previously, there have been many studies concerning teacher self-efficacy and classroom Internet use by looking at the amount and type of computers and Internet connections in K-12 schools. This research study examined the relationship between teacher factors (teaching experience, grade level taught, etc.) and school-level factors (poverty level of students, technical support, etc.) and their connection to level of Internet use in teaching the curriculum. 


\section{Research Questions}

The following two research questions guided the study:

1. What is the relationship between teachers' level of classroom Internet use and the following independent variables:

a. grade level taught (elementary, middle, high school)?

b. years of teaching experience?

c. type of technical support received at the teacher's school?

d. Internet-related professional development training?

e. number of Internet-accessible computers in the classroom?

f. socioeconomic status of student population?

g. teacher Internet self-efficacy?

2. What is the relationship between teachers' self-efficacy with using the Internet in the classroom and the following independent variables:

a. years of teaching experience?

b. type of technical support received at the teacher's school?

c. Internet-related professional development training?

Hypotheses

This study will attempt to refute the following hypotheses derived from research questions one and two.

Hypotheses for Research question 1

Research Hypothesis 1.a: Secondary teachers will have a higher level of Internet use in the classroom than middle school teachers, and middle school teachers will have a higher level of Internet use in the classroom than elementary teachers. 
Research Hypothesis 1.b: The more years of teaching experience a teacher has, the higher the teacher's level of Internet use in the classroom.

Research Hypothesis 1.c: Teachers who have full-time on-site technical support will have a higher level of Internet use in the classroom than those that do not.

Research Hypothesis 1.d: As the amount of teacher Internet training increases, whether inservice professional development, college credit courses, or multiple-day workshops, the teacher's level of Internet use in the classroom increases.

Research Hypothesis 1.e: The more Internet-accessible computers a teacher has in the classroom, the higher the teacher's level of Internet use in the classroom.

Research Hypothesis 1.f: Teachers who work in schools that have a high student socioeconomic status, as measured by the number of students on free or reduced lunch, have a higher level of Internet use in the classroom than schools with a low student socioeconomic status.

Research Hypothesis 1.g: The higher the level of teacher self-efficacy with using the Internet, the higher the teacher's level of Internet use in the classroom.

\section{Hypotheses for Research question 2}

Research Hypothesis 2.a: The more years of teaching experience a teacher has, the higher the teacher's level of Internet self-efficacy.

Research Hypothesis 2.b: Teachers who have full-time on-site technical support will have a higher level of Internet self-efficacy.

Research Hypothesis 2.c: As the amount of teacher Internet training increases, whether inservice professional development, college credit courses, or multiple-day workshops, the teacher's level of Internet self-efficacy will also increase. 


\section{Assumptions of the Research}

The study made the following assumptions:

1. Survey respondents answer questions honestly and to the best of their knowledge.

2. What respondents indicate they are doing is actually what they do in the classroom.

3. Internet use in the classroom enhances learning.

4. Empirical-based knowledge can be a guide to teachers and administrators.

\section{Limitations of the Study}

The study was limited by the following factors:

1. The study is limited to West Virginia schools and is not intended to represent schools in other states and territories.

2. The survey instrument is limited by the reliability of self-reported answers.

\section{Definitions}

$\underline{\mathrm{CE} \text { credits }}$ - Continuing Education credits. In most instances school district professional development seminars are counted as one CE credit per hour of training. $\underline{\mathrm{CIS}}$ - Classroom Internet Survey. The survey instrument used in this study, measuring teacher level of classroom Internet use and teacher self-efficacy with using Internet technology. Digital Divide - The gap in Internet technology and use between groups, typically between low and high SES schools. It can also be used to describe differences between other factors, such as race, sex, or age.

Elementary schools - Schools that primarily teach grades Kindergarten through fifth grade. $\underline{\text { High schools }}-$ Schools that teach students in grades nine through twelve 
Internet - Things pertaining to computer-mediated communication. This includes, but is not limited to, the World Wide Web, e-mail, interactive on-line chats, and on-line bulletin boards. Internet-accessible computers - Computers that are connected to the Internet, regardless of method or bandwidth.

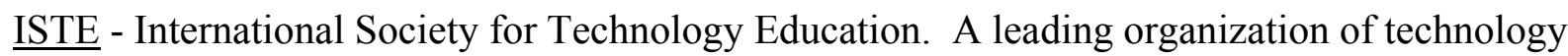
professionals dedicated to the promotion of technology in the educational process.

$\underline{\mathrm{LOU}}$ - Level of use. The compilation score from Part 2 of the CIS instrument.

Middle schools - In this study, middle schools are primarily grades sixth through eighth.

NCLB - The No Child Left Behind Act of 2001. This law reauthorizes the Elementary and Secondary Education Act of 1965 (ESEA) but changes the ways funds are allocated to schools and calls for school accountability on student achievement based on student test scores. NETS - National Educational Technology Standards. These are guidelines created by the International Society for Technology Education (ISTE) for student technology objectives in grades K-12.

$\underline{\text { PITEBS }}$ - Personal Internet Teacher Efficacy Belief Scale. An efficacy belief survey instrument that was the basis for Part 3 of the CIS instrument used in this study. Professional Development - In-service training conducted through local, state, or federal initiatives, as well as college coursework.

Self-efficacy - The belief in one's own ability to perform an action or activity necessary to achieve a goal or task.

$\underline{\text { SES }}$ - Socioeconomic status. A school's relative affluence determined by the number of students eligible for the Federal free and reduced lunch program. 
Low SES - For purposes of this study, schools with more than 50\% of students eligible for free and reduced lunch. This percentage is lower than the $60 \%$ rate used by the Federal government to determine school Title I eligibility.

High SES - Schools that have less than 50\% of students eligible for free and reduced lunch. Technical support - The method of physically maintaining computers and computer networks. Title I - Federal program to provide additional resources for schools that have a high (greater than $60 \%$ ) student eligibility rate for the federal free and reduced lunch program. 


\section{CHAPTER 2}

Review of Literature

\section{Classroom Internet Use and Factors Affecting It}

\section{Internet Use and Student Grade Level}

As stated in the first chapter, practically all schools have Internet access today regardless of grade level, but that was not always the case. In 1994, 49\% of secondary schools had Internet access, while only $30 \%$ of elementary schools had access. By 2002 over $99 \%$ of elementary and secondary schools had access to the Internet (NCES, 2004a). When examining where the access is in relationship to the classroom, once again there is almost no difference between elementary and secondary schools. In 1994, 3\% of elementary classrooms had Internet access as opposed to $4 \%$ of secondary. In $2002,92 \%$ of elementary classrooms and $91 \%$ of secondary classrooms were wired for Internet use (NCES, 2004a).

Not only is the access to the Internet nearly identical, but the access to professional development and the teacher participation rate is similar for elementary and secondary schools. An NCES study found that, in $2002,87 \%$ of public schools reported that they offered professional development on integrating the Internet into the classroom to elementary school teachers and $86 \%$ had offered the training to secondary teachers. Teacher participation was also high in both cases. The report found that in $41 \%$ of the elementary schools, over half the teachers participated in the professional development while $38 \%$ of secondary schools reported a similar participation rate (NCES, 2004a).

Interestingly, even though access to the Internet and professional development training is nearly identical across grade levels, there are still differences between elementary and secondary schools. Even with equal access to the Internet, elementary schools are less likely to have a web 
page compared to secondary schools ( $85 \%$ to $93 \%)$. When comparing schools that do have web sites, secondary schools are almost twice as likely to update their web sites at least once a week when compared to elementary schools (59\% to $36 \%$ ). Thirty-five percent of elementary schools do not even update their web site on a monthly basis, as opposed to $22 \%$ of secondary schools not maintaining their site on at least a monthly basis (NCES, 2004a).

Internet Use and Teaching Experience

Unfortunately, teachers are technologically challenged even before they set foot in the classroom. Reehm, Long, and Dickey (2001) found that pre-service teachers score lower on some measures of computer skills and knowledge than their peers. The conclusion was that the lack of elective computer courses for pre-service teachers and the lack of emphasis on technology in core education courses caused the lower scores. They also looked at the differences between education and non-education majors, and between pre-service and in-service teachers. A computer survey of level of confidence on 27 specific technology areas was given to 180 undergraduate pre-service teacher education students, 70 graduate education students, and 81 undergraduate non-teacher education students. While this study found that non-education majors develop a higher level of computer skills than the pre-service teachers, it also showed that graduate in-service teachers did not have significantly higher skills than the undergraduate education majors. This would suggest that graduate education programs do not emphasize a continuation of the technology learning process.

Internet Use and Technical Support

Schools use a variety of ways to provide technical support for teachers. Nationwide in $2002,38 \%$ of schools had a full-time school technology person, $26 \%$ had district level staff that provided support, $18 \%$ designated a teacher as technology support for part of their regular duties, 
$11 \%$ used a part-time person, and 7\% used outside staff or volunteers (NCES, 2004a). Teacher use of technology has been found to be directly affected by access to technical support (Norris, Sullivan, Poirot, \& Soloway, 2003). In that study, 3,665 teachers in four states (California, Florida, Nebraska, and New York) were surveyed about their use of technology in the classroom, and respondents came from schools that were both rural and urban. The study results indicated that access to technical assistance was a significant predictor of classroom Internet use. In another study, teachers who had access to assistance were significantly more likely to use classroom time with students on the Internet. In the study $56 \%$ of the teachers with available assistance used the Internet compared to $42 \%$ of teachers in schools that did not have easy access to support (NCES, 2000b)

\section{Internet Use and Professional Development}

The growth of the Internet over the last decade has spawned many attempts at helping teachers harness the power of the Internet as a classroom resource. On the Federal level alone several Internet training programs have been initiated and funded since 1990, including Preparing Tomorrow's Teachers to Use Technology (PT3), Enhancing Education through Technology (Ed. Tech), Technology Innovation Challenge Grant Program (TICG), and the Improving Teacher Quality State Grants (U.S. Department of Education, 2004). As the use of the Internet in the classroom grows, so has the need to develop ways to incorporate the new technologies into a usable framework that helps students grow and learn. The speed of these classroom changes has left teachers feeling unprepared and anxious about using computers in the classroom. In one study, only $20 \%$ of teachers surveyed felt prepared to integrate technology into the classroom (Norman, 2000). Even in studies that produced better results (33\% felt prepared), a majority of teachers still felt inadequate in using computers (NCES, 2000a). 
The Federal government acknowledged the importance of teacher training and professional development in 1988 by creating the Eisenhower Professional Development Program and reauthorizing it as part of Title II of the Elementary and Secondary Education Act (ESEA) in 1994. This program was devoted solely to teacher training and increasing the skills of classroom teachers, and its goal was to support professional development and to improve student learning through these efforts (U.S. Department of Education, 2000).

Analyzing the effectiveness of the Eisenhower Professional Development Program yielded some interesting results on teacher professional development. One report, "Designing Effective Professional Development: Lessons from the Eisenhower Program", concluded that six factors determined the effectiveness of professional development. The factors included the type of reform, the duration of the professional development interaction, collective participation of participants and administration, active learning, coherence of material, and content focus (U.S. Department of Education, 1999). This study based its results on ten in-depth case studies throughout the United States.

Another report of the Eisenhower program was titled, "Does Professional Development Change Teaching Practice? Results from a Three-Year Study" (U.S. Department of Education, 2000). This longitudinal study looked at relationships between professional development and teaching practice. The researchers looked at 30 schools in five states over three years, and in their report noted three general conclusions. The first conclusion was that professional development emphasizing high-order teaching strategies increased in-service teachers' use of them in the classroom. The second conclusion was that teachers do not experience quality professional development on a regular basis and that teacher development experiences vary widely, even within the same school. Finally, the study noted that very little overall change 
occurred during the course of the study, though some changes in teacher practice were noted among teachers from one year to the next.

The efforts to change the way we teach and use technology have increased dramatically over the last few years. In an effort to improve student achievement in schools President George W. Bush signed into law the No Child Left Behind Act of 2001 (NCLB). This law reauthorized the Elementary and Secondary Education Act of 1965 (ESEA) but changed the way funds are allocated to schools and held schools accountable for student achievement. Title II of the law focused on improving teacher quality as determined by subject area content knowledge and teaching effectiveness. To accomplish this, NCLB created the Improving Teacher Quality State Grants program to allow individual states to fund professional development activities that are research driven, measurable, promote the higher qualifications needed by teachers, and the improvement of student achievement. Programs under the NCLB umbrella, including the Improving Teacher Quality State Grants program totaled almost \$23.7 billion for the 2003 fiscal year (U.S. Department of Education, 2002).

Using technology effectively in the classroom is also a major thrust of NCLB. As part of the reorganization of the federal effort to improve education implemented by NCLB, the Enhancing Education Through Technology Program (Ed Tech) was established. Under this program, funds are provided to states to use in elementary and secondary schools to support and implement effective use of technology. The guidelines call for $25 \%$ of any grant to go towards teacher professional development, which is short of the $30 \%$ recommended by the President's Advisors on Science and Technology (1997) but significantly higher than the 14\% typically spent on technology professional development by schools and educational agencies (Skinner, 2002). With a 2003 budget of almost $\$ 700$ million, the need to understand and develop effective 
professional development is important so that these funds are not wasted (U.S. Department of Education, 2002).

To further underscore the importance that the federal government places on integrating technology in education, the Advanced Education Technology Initiative was established on October 23, 2003. This committee's task is to promote the development and application of technology in education, and the committee is co-chaired by the Under Secretary of Commerce, Philip Bond, and the Department of Education's Director of Educational Technology, John Bailey. The committee has representatives from several federal departments, and encourages cooperative ventures between agencies and the business community (U.S. Department of Education, 2003).

Internet Use and Internet-accessible Computers in the Classroom

Today, most teachers and students have easy access to the Internet. The explosive growth of computers and the Internet into the classroom over the last ten years has been made with a combination of initiatives from federal, state, and local authorities, as well as help from the private sector. At the same time the connection speed of the Internet in the classroom has also increased dramatically. A study by the National Center for Educational Statistics found that $74 \%$ of schools used a dial-up connection in 1996, where 94\% used high speed lines in 2002 (NCES, 2004a). This improvement directly relates to the changing needs of the workplace. In 2001, $54 \%$ of all American workers used computers in their jobs (NCES, 2004b).

Today, well over $90 \%$ of K-12 classrooms have at least one computer that can access the Internet (NCES, 2004a). Even with this classroom access, most students report that they access the Internet at school in places other than the classroom. One study found that students accessed the Internet in the classroom only $22 \%$ of the time, but $69 \%$ of the time they used a central 
location (computer laboratory, media center, etc.) Even teachers report that their school access to the Internet was accomplished in their classrooms only $20 \%$ of the time. Fifty-four percent of teachers reported their Internet access point was an office or department work space (Thomas et al., 2002).

Some research has found the number of computers in the classroom contributes to teachers' use of computers in their lessons. Even if students have easy access to a computer lab the number of computers in the classroom is a predicting factor for the amount and type of computer use. Becker (2001) found that one of the factors that affect classroom use of computers is the number of computers in the classroom. Becker (2000) found that teachers who used computers most frequently had at least five computers in their rooms.

Internet Use and Socioeconomic Status of Students

One significant problem with the explosion of the Internet and computers in the classroom is the concept of a separation of schools that can afford the new technology with those that cannot. This separation is commonly referred to as the "digital divide" (Roblyer, 2003), and the National Center for Educational Statistics (NCES, 2004a) found that in 2002 the ratio of students to computers with Internet connection was significantly higher in schools that had a high percentage of students in poverty than schools that had a low percentage in poverty (5.5 to 1 compared to 4.6 to 1). To help promote equal access to the Internet for all the United States Congress passed the Telecommunications Act of 1996. This law allowed schools to receive discounts, referred to as the E-rate, on equipment and Internet services based on the number of students receiving free and reduced lunch, with the added modifier that rural schools receive a slightly higher discount than equivalent urban schools. The technology and Internet providers are then reimbursed the discount amount from a special fund created with monies collected from 
users of telecommunications services, known as the Universal Service Fee. The discounts range from $20 \%$ to $90 \%$, and has been on-going since 1998 . Schools and libraries received over $\$ 2.6$ billion in discounts for fiscal year 2003 (Universal Service Administrative Company [USAC], 2004).

Beyond the divide separating technology use between rich and poor schools, there are other factors that affect the amount and use of Internet in schools, including school racial demographics. While federal, state, and local efforts to overcome this gap (E-rate for example) have closed the technology gap over the last decade, there are still differences in the amount and quality of access between rich and poor school districts, as well as white versus minority students. The digital divide separates minority groups from the mainstream, and this lack of access may cause feelings of inadequacy with computers as well as create barriers to improved educational resources (Torkzadeh, 1999). An NCES study (2004a) found that, while students of all ethnic backgrounds were almost equal in their use of computers at school, ranging from $78.8 \%$ for Hispanics to $84 \%$ for whites in 2001 , schools with high minority enrollment were far less likely to make Internet access available after school hours (62\%) than schools with low minority representation $(80 \%)$.

There has been improvement with regards to access to computers and race in recent years. The gap has narrowed between minority students and white students and their access to computers at school. According to the NCES, $61.6 \%$ of white children used computers at school in 1993, compared to $51.5 \%$ for African Americans, and 52.1\% of Hispanics, a difference of approximately $10 \%$ between whites and the other two ethnicities. In 2001 the difference in the numbers was narrowed to $1.7 \%$ between white and African American students and 5.3\% for white versus Hispanic students. When looking at access to computers at school by income in 
1993 and 2001 the narrowing of the divide was even more dramatic. In 1993, students whose household income was less than $\$ 15,000$ used computers at school less than $56 \%$ of the time, while students whose household income was greater than $\$ 75,000$ used computers at school almost $65 \%$ of the time. In 2002 , the difference was approximately $82 \%$ for the low income group compared to $80 \%$ for the higher income group (NCES, 2004a). Yet, in situations where there has been significant teacher training on Internet integration, there is still a divide in terms of Internet use in schools between groups. Foster (2002) stated that the focus on solving the digital divide rests with the students' perception of its use in their lives, that only students who view technology as important to their future will continue to use and develop their skills.

But the digital divide also encompasses the difference between children who have access to computers and the Internet at home versus those that do not. In 2001 blacks and Hispanics were almost half as likely as whites or other minorities to have access to computers at home ( $45.5 \%$ black, $45.7 \%$ Hispanic versus $78.5 \%$ for whites and $74.5 \%$ for other minorities). When looked at by household income the differences are also stark. In the same sample year, 2001, less than $40 \%$ of children in homes making less than $\$ 15,000$ per year had access to a computer, while $89 \%$ of children in homes that make over $\$ 75,000$ had one (NCES, 2004a). In 1999, the Northern Virginia Community College Office of Institutional Research commissioned a study of factors affecting home and work Internet access of its college students (2000). This study consisted of a survey given to 290 students at the college and examined differences in both gender and racial access. While no significant difference was found in access related to gender there were significant differences in home access to computers between whites $(89 \%)$, blacks (79\%), Asians (80\%) and Hispanics (83\%). 
Internet Use 26

Internet Use and Self-efficacy

There have been several long-term studies of technology use, proficiency, and feelings of efficacy in regards to computer and Internet use with mixed results. In a three year study of preservice teachers, it was found that feelings of self-efficacy and computer technology increased significantly between the first and second year, and maintained a high level of efficacy during the third year (Milbraith and Kinzie, 2000). Another study, by American Institutes for Research (AIR) for the U.S. Department of Education (1999) examined the Eisenhower Professional Development Program, the federal government program devoted to developing the knowledge and skills of in-service teachers. This study of 30 elementary, middle, and secondary schools, and over 430 teachers during the 1996-97, 1997-98, and 1998-99 school years found little change in overall teaching practice even with professional development. Their conclusion indicated that the teachers' inability to develop improved strategies was related to the wide variation in the amount and quality of professional development received over the course of the study.

\section{Self-efficacy}

Self-efficacy may be defined as a belief in one's own ability to perform an action or activity necessary to achieve a goal or task (Bandura, 1997). Computer self-efficacy and Internet self-efficacy are closely related, as Internet self-efficacy would be affected by a user's computer self-efficacy. Someone who has a low self-efficacy with computers would likely be uncomfortable with using the Internet, since it would involve using the computer. A study of 776 employees at a major university found that employees with high computer self-efficacy performed computer related tasks at a higher level than employees with low computer selfefficacy (Harrison, Ranier, Hochwarte, \& Thompson, 1997). 
Some studies have shown a link between a high level of computer self-efficacy on the part of a teacher and higher student academic achievement (Cannon \& Scharman, 1996; Ross, Hogaboam-Gray, \& Hamay, 2001). Low computer self-efficacy has been shown to have a negative impact on student performance. In the study by Ross et al., students in grades K-3 were studied to determine how changes in teacher computer efficacy affected them. Specifically, the students were evaluated on changes in basic and advanced computer skills and computer selfefficacy as they moved from one grade to another. Students who moved from teachers with high self-efficacy to teachers with a low level of self-efficacy did not improve their skills and efficacy as much as students moving from teachers with low to high levels. In another study, Norman (2000) examined student math achievement test scores and found a link between higher scores and teachers who had professional development in technology and computers.

\section{Factors Affecting Teacher Self-efficacy with Computers and the Internet}

\section{Self-efficacy and Teaching Experience}

Teacher experience plays a major role in the perception of Internet use in schools and the difficulty in integrating technology into the classroom. An NCES study (2000) found that experienced teachers reported that a lack of release time to learn to use or prepare to use technology was a "great barrier" to integrating technology in the classroom, even more so than newer teachers. The study indicated that $41 \%$ of teachers with $10-19$ years of teaching experience and $39 \%$ of teachers with over 19 years of teaching experience stated the lack of release time was a "great barrier" as opposed to $25 \%$ of the teachers with less than three years of teaching experience and $34 \%$ of teachers with four to nine years of teaching experience. 


\section{Self-efficacy and Technical Support}

Perception of barriers to technology and Internet integration may prevent teachers from attempting to use technology in the classroom. The amount and type of technical support available may play a role in teacher comfort with technology and potential for use. In 1999, the NCES completed a survey of teachers nationwide on their use of technology in the classroom. This study looked at all types of technology use and the problems teachers reported having with its use. The study surveyed 2,109 teachers encompassing all 50 states and the District of Columbia, and included elementary, middle, and secondary school teachers. This study found that teachers who did not have an on-site technology support person were two to three times more likely to report that institutional and technical support was a significant obstacle in integrating technology. Specifically, the NCES report found that $39 \%$ of teachers in schools that had no technical support person in the school reported technical support as a significant barrier to integration, compared to $12 \%$ of teachers in schools that did have a technologist on staff (NCES, 2000b).

Self-efficacy and Professional Development

Christensen (2003) studied a professional development program that had in-service teachers participating in two days of needs-based technology integration training with a followup day of training every six weeks throughout the academic year, and compared the results with that of a control group of teachers that did not receive any training. The results indicated that the training had a positive effect on teacher attitudes and anxiety, while also indicating a time-lagged effect on students' attitudes and anxiety with computers.

Would more computer classes and professional development training overcome both the deficit in skill and the low self-efficacy towards computers by teachers? Research clearly 
indicates training teachers to use technology does lower anxiety and increase efficacy while improving their skills. A study by Gonzales, Pickett, Hupert and Martin (2003) found that teachers who had training with technology were much more confident about using technology in their classrooms. Leh (2000) and Ross et al. (2001) found that pre-service and in-service teachers taking a college technology integration course had a higher comfort level, more confidence, and more positive attitude toward the use of computers, and were more inclined to integrate new technologies into their classrooms. Sottile, Watson, and Iddings (1998), Koul and Rubba (1999), and Dean (2001) all found that professional development workshops for inservice teachers increased the computer self-efficacy levels of the participants.

\section{Gender Differences and Internet Use}

There has been a large body of research done on the effect that gender plays on computer use. This research has produced a variety of results, most of which indicate that a gap between men and women in terms of use, perception, and comfort level did exist. Interestingly, as the Internet use has become more common in our lives, the research shows an overall reduction in the gender gap in most measures of computer use and computer confidence (Busch, 1995; Office of Institutional Research, 2000; Colley \& Comber, 2003). During the early to mid-1990s most research indicated that women had more negative feelings towards computers (Durndell, 2002 and Todman \& Monaghan, 1994).

Starting in the mid-1990s and continuing to today, studies show the differences in feelings about computers and computer use between the sexes shrinking. A study by Busch (1995) found that, when controlling for previous experience there was no significant difference between men and women in the areas of computer anxiety and computer confidence. A study of computer use of students at the Northern Virginia Community College (NVCC) in 1999 found a 
slight difference in home access between men and women. This study surveyed 290 community college students and found that $92 \%$ of the male respondents had Internet access at home, compared to $83 \%$ of women (Office of Institutional Research, 2000). Another study of 500 middle and high school students found that the gender gap in computer use had been reduced since the early 1990s but that some differences remained in concerns towards attitudes about computers (Colley \& Comber, 2003).

\section{Promoting Inquiry-based Learning Through Computer/Internet Use}

The use of the Internet in the classroom is promoted as a benefit to constructivist teaching as students can use it as a research and communication tool to further their understanding of a subject. Constructivism may be defined as the process of individual learning by participating in certain experiences. That is, a person creates their own mechanisms for learning and the information is processed through personal experience, previous knowledge, and aptitude (Sfard, 1998). In a constructivist lesson goals are not simply the retention and regurgitation of facts, but focus on problem solving and critical thinking skills developed through interaction with the problem and with other students. The learners become owners of the lesson, having some say in the end goals and objectives of their work. The focus in a constructivist classroom is thus on process and interaction, not on the end result. The Internet, with its vast, easy-to-access stores of information, enhances students' ability to develop their own information efficiently to complete projects, web quests, or other constructivist-type assignments.

The question then is, how to bring the Internet to all students equally, so as to allow better constructivist teaching using this technology? Hinson and Daniel (2001) studied a program that gave equal home Internet access to fourth grade students through a program called WISH TV. The project was created to test methods of providing Internet access to poor students. 
The WISH TV service used television as the conduit to the Internet, eliminating the need for telephone, DSL, or broadband service for access, and for this study, the families were provided the service free for a year. The service allowed students and their families to e-mail, surf the Internet, and communicate and share information through a wireless keyboard and mouse. The results of the study indicated that, having eliminated equitable access as a dividing issue, all students were moving towards inquiry learning and were better able to complete homework assignments. Parents reported that they liked the interaction with the teacher and the opportunity to see what their child's assignments were and they were much more involved with their children through helping with homework. Teachers found that students were actively engaged in the problem-solving type of work assigned, completing 100\% of this type of homework as well as finding more Internet resources than just the ones posted for each exercise. Students also wanted to use the service during school hours, even during recess. The principal noted the lower amount of student disruptive behavior and referrals of unruly students to her.

\section{National Educational Technology Standards (NETS)}

Educators and policymakers have emphasized more and more that student skills with technology are an important part of the educational process. For example, one of the main goals of the U.S. Department of Education's Office of Educational Technology is the increased use of technology to help them attain state content standards (U.S. Department of Education, 2004). Unfortunately, until 1998, there were no national standards regarding what students should know and be able to do with technology. In that year, the International Society for Technology in Education (ISTE) produced the National Educational Technology Standards (NETS) for PreKindergarten to grade 12 students (Roblyer, 2000). ISTE is the largest educational technology 
organization in the world, and developed the NETS project over four years (1994-1998) with input from over 2,000 education professionals and administrators (ISTE, 2000).

To explain the standards and provide guidance to educators, the NETS technology standards, published in book form as the National Educational Technology Standards for Students (ISTE, 2000), are divided into six broad categories: Basic operations and concepts; Social, ethical, and human issues; Technology productivity tools; Technology communication tools; Technology research tools; and Technology problem-solving and decision-making tools. To help ascertain student performance, it is then further defined by using performance indicators to show what technology literate students should be able to do. These indicators, or profiles, are given for four different grade ranges: Pre-Kindergarten-2, grades 3-5, grades 6-8, and grades 912.

The NETS project also includes standards and performance indicators for teachers, also published by ISTE in book form as the National Educational Technology Standards for Teachers. This latest effort at providing technology guidance for educators was first published in 2000. The first effort at teacher technology standards by ISTE was published in 1993 and contained 13 indicators of technology performance. The standards were revised into 18 indicators divided into three categories in 1997, and were followed up with the current standards, divided into six categories and 23 indicators. This last revision was formatted and modeled on the NETS for students guidelines (International Society for Technology in Education, 2002).

The National Educational Technology Standards for Teachers (NETS*T) are divided into the following six categories: Technology operations and concepts; Planning and designing learning environments and experiences; Teaching, learning, and the curriculum; Assessment and Evaluation; Productivity and professional practice; and Social, ethical, legal, and human issues. 
The performance indicators are separated into four profiles based on student teacher preparation stages. The first profile, General Preparation, contains indicators of student technology achievement before entering the professional education course of study. Typically, students would work through their subject area courses and lower division general studies requirements when pursuing the goals of this profile. The second profile, Professional Preparation, deals with coursework and performance typically found after admission to the professional education program. The third profile, Student Teaching/Internship, concerns performance indicators during student teaching and initial licensure. Finally, the First-year Teaching profile deals with indicators for teachers in their initial posting as a teacher (ISTE, 2002).

\section{Qualitative Versus Quantitative Research}

The term qualitative research defines a variety of research methods that involve collection of descriptive data not easily handled by statistical procedures, and various qualitative methods include interviews, participant observation, and archival research. Research of this type usually involves sustained contact with subjects in their natural environment and typically encompasses multiple methods of data collection. Qualitative researchers do not approach a study with a particular investigative question or hypothesis to test, but rather look to investigate a general topic and allow the data to focus the study. The researcher is not concerned with facts as much as the context in which the facts lie (Bogdan \& Biklen, 1998).

Bogdan and Biklen (1998) outline five main characteristics of good qualitative research. The first characteristic is that the research is naturalistic, or set in the natural surroundings of the subjects. Researchers spend their time in the field to help gather contextual information. The second characteristic is that the data is descriptive, taking the form of quotes, pictures, and other anecdotal evidence. Another characteristic is the emphasis on process, not just the outcome of 
the data. Qualitative research is inductive rather than deductive, where conclusions are built from the collected data, not outlined before research begins and then proved or disproved. Finally, qualitative research looks at the meaning of the observations and, in this regard, observations are of how people deal with their life situation.

On the other end of the research spectrum is quantitative research. Quantitative research is based primarily on the scientific method, the testing of a pre-stated question or hypothesis. Using the scientific method as its basis, quantitative research utilizes four steps in developing research experiments. The first step involves defining the problem of the study. The problem, or hypothesis, is a statement that can be proved or disproved by the gathering of data. The second step involves the execution of the research procedures. In quantitative research the procedures could include, but are not limited to, surveys, comparisons of data, and examining documents or data sets. The next step is to analyze the data collected using statistical methods such as correlations, analysis of variance, etc. Finally, conclusions are drawn from the data analysis on whether the Research Hypothesis of the study was supported by the data collected (Gay, 1988).

Gay (1988) classified quantitative research methods into five general categories. Historical research looks at data to explain or understand past events by looking at documents and conducting interviews. This type of research does not normally use survey instruments to collect data, but instead, looks at data that describe or detail the event in question. Examples of this type of data would include, but are not limited to, historical documents, interviews with witnesses, and even old newspaper articles. Another category of research is descriptive research. In this type of research, data are collected to create an idea of the present state of something. An example of this would be to determine how citizens will vote in the next presidential election. A 
researcher could use election polls or public opinion surveys to determine the current feelings of the voters.

The third category is correlational research, where researchers attempt to find relationships between multiple variables (Gay, 1988). This type of research deals only with the predictability of factors occurring together, not with cause and effect. For example, high school grades and college grades are highly related, meaning that students who have a high GPA in high school often have a high GPA in college. The high school GPA is not the cause of the high college grades, but one can use it to predict how a student might do in college. The final two categories, experimental research and causal-comparative, are quite similar. In experimental research the independent variable is changed in order to study its effect on the survey group. Giving one group of patients a medication and another a placebo is an example of experimental research. In causal-comparative research the independent variable is not manipulated by the experimenter. An example of this might be participant gender, or studying a group of cancer patients, where the cancer is the independent variable, as it would be unethical to induce cancer in research participants.

Based on the research, this study will use a correlational research model, specifically using stepwise multiple regression analysis of the variables. The stepwise regression will allow the researcher to examine the predictor variables to determine which ones specifically aid in the prediction of the dependent variable and how combinations of variables strengthen or weaken the relationship with the dependent variable.

\section{Summary}

The Internet has gone from an interesting educational phenomenon to widespread classroom implementation in little more than a decade. Technical issues of connectivity, 
classroom access, and financial support for purchasing and installing necessary equipment have largely been resolved. Programs such as the E-rate have closed the technology gap between rich and poor school districts, and so today, a classroom without at least one computer connected to the Internet is the exception, not the rule.

It is not enough to know how many computers are connected in a given classroom, but how the technology is being used by teachers, and what factors play a role in its use. Research is now being done on the integration of the Internet into regular classroom teaching and, overall, the research regarding teacher's level of classroom Internet use shows that several factors may affect its use. The grade level taught, poverty level of the student body, efficacy of the teacher with the Internet, and technical support received play a role in how much the Internet is used and to what degree. Professional development on the basics of Internet use and how to integrate it into teaching is also a significant factor in overall teacher use. While professional development opportunities are available, there are indications that the amount and quality of the training may suffer from a lack of financial resources.

Assessing the factors that drive whether teachers use the Internet in the classroom is important in predicting needs for training, resources, or other support to increase the effectiveness of this ever-changing technology. Administrators need to know how to successfully change teaching methods to use the Internet more so that investments in technology and training are successful. Also, understanding the relationships between factors will allow a better understanding into why some schools and teachers are more successful than others with Internet integration. 


\section{CHAPTER 3}

Method

The purpose of this study was twofold. One purpose was to determine to what degree a teacher's level of Internet use was related to grade level taught by the teacher, years of teaching experience, type of technical support available to the teacher, Internet-related professional development training, the number of Internet-accessible computers in the classroom, school socioeconomic status, and teacher self-efficacy with using the Internet. The second purpose of the study was to determine the degree that self-efficacy with using the Internet was related to years of teaching experience, type of technical support available to the teacher, and Internetrelated professional development training.

This study involved West Virginia teachers of all grades and geographic areas within the state, using a quantitative research method to examine predictors of classroom Internet use. The study used the Classroom Internet Survey instrument (CIS), which contained a set of demographic questions, followed by a set of questions examining the level of classroom Internet use, and questions to determine the classroom Internet self-efficacy of the teachers. This chapter details the participant sample, the survey instrument, the method of obtaining the participant sample, and the means to analyze the data.

\section{Research Design and Data Analysis}

The design of the research allowed for a large sample of teachers from throughout West Virginia. The teachers work in schools whose student population has a high SES level (schools with a student population with less than $50 \%$ of students eligible for either free or reduced lunch) or schools that have a low SES level (schools with more than $50 \%$ of students eligible for free and reduced lunch). The sampling of participants came from elementary, middle, and secondary 
schools, allowing measurements of self-efficacy and levels of Internet use from all grade levels. The CIS survey instrument (see Appendix A) collected basic demographic information, as well as information on teacher self-efficacy with the Internet and classroom Internet use. The parts of the survey dealing with Internet use and self-efficacy collected data by using a five point Likert scale for each question, which was analyzed using stepwise multiple regression analysis. The use of stepwise multiple regression allowed analysis of the factors and to determine relationships between factors and their relationship with the dependent variables.

\section{Independent and Dependent Variables for Research Questions}

Table 3.1 lists the dependent (DV) and independent (IV) variables for the study. The CIS instrument is composed of three parts: Part 1 contains a series of demographic questions, Part 2 contains the Personal Internet Teaching Efficacy Beliefs Scale (PITEBS), and Part 3 holds the Level of Internet Use (LOU) questions.

\section{Research Questions}

A reiteration of the two research questions that guided the study:

1. What is the relationship between teachers' level of classroom Internet use and the following independent variables:
a. grade level taught (elementary, middle, high school)?
b. years of teaching experience?
c. type of technical support received at the teacher's school?
d. Internet-related professional development training?
e. number of Internet-accessible computers in the classroom?
f. socioeconomic status of student population?
g. teacher Internet self-efficacy? 
2. What is the relationship between teachers' self-efficacy with using the Internet in the classroom and the following independent variables:
a. years of teaching experience?
b. type of technical support received at the teacher's school?
c. Internet-related professional development training?

Table 3.1

Dependent and Independent Variables of Study

\begin{tabular}{|c|c|c|}
\hline Variable & Description & How measured \\
\hline DV 1 & Teacher's level of Internet use & Part 2 of survey \\
\hline IV & Grade level of students taught by the teacher & Part 1 of survey \\
\hline IV & Years of teaching experience & Part 1 of survey \\
\hline IV & Type of technical support available to the teacher & Part 1 of survey \\
\hline IV & $\begin{array}{l}\text { Internet-related professional development training received } \\
\text { by the teacher }\end{array}$ & Part 1 of survey \\
\hline IV & Number of Internet-accessible computers in the classroom & Part 1 of survey \\
\hline IV & Socioeconomic status of the student population & $\begin{array}{l}\text { Percentage of } \\
\text { students eligible } \\
\text { for Federal } \\
\text { free/reduced lunch }\end{array}$ \\
\hline IV & Teacher self-efficacy with using the Internet & Part 3 of survey \\
\hline DV 2 & $\begin{array}{l}\text { Teacher's level of self-efficacy regarding classroom Internet } \\
\text { use }\end{array}$ & Part 3 of survey \\
\hline IV & Years of teaching experience & Part 1 of survey \\
\hline IV & Type of technical support available to the teacher & Part 1 of survey \\
\hline IV & $\begin{array}{l}\text { Internet-related professional development training received } \\
\text { by the teacher }\end{array}$ & Part 1 of survey \\
\hline
\end{tabular}




\section{Hypotheses}

Based on the research questions, the following hypotheses were tested in the study: Hypotheses for Research question 1

Research Hypothesis 1.a: Secondary teachers will have a higher level of Internet use in the classroom than middle school teachers, and middle school teachers will have a higher level of Internet use in the classroom than elementary teachers.

Research Hypothesis 1.b: The more years of teaching experience a teacher has, the higher the teacher's level of Internet use in the classroom.

Research Hypothesis 1.c: Teachers who have full-time on-site technical support will have a higher level of Internet use in the classroom than those that do not.

Research Hypothesis 1.d: As the amount of teacher Internet training increases, whether inservice professional development, college credit courses, or multiple-day workshops, the teacher's level of Internet use in the classroom increases.

Research Hypothesis 1.e: The more Internet-accessible computers a teacher has in the classroom, the higher the teacher's level of Internet use in the classroom.

Research Hypothesis 1.f: Teachers who work in schools that have a high student socioeconomic status, as measured by the number of students on free or reduced lunch, have a higher level of Internet use in the classroom than schools with a low student socioeconomic status.

Research Hypothesis 1.g: The higher the level of teacher self-efficacy with using the Internet, the higher the teacher's level of Internet use in the classroom. 


\section{Hypotheses for Research question 2}

Research Hypothesis 2.a: The more years of teaching experience a teacher has, the higher the teacher's level of Internet self-efficacy.

Research Hypothesis 2.b: Teachers who have full-time on-site technical support will have a higher level of Internet self-efficacy.

Research Hypothesis 2.c: As the amount of teacher Internet training increases, whether inservice professional development, college credit courses, or multiple-day workshops, the teacher's level of Internet self-efficacy will also increase.

\section{Participants}

The participants in this study were 1,036 public school teachers in the state of West Virginia and represented all grade levels and taught language arts, mathematics, science, or social studies, or some combination of these subjects. To collect the sample of teachers, a complete listing of all schools was obtained from the West Virginia Department of Education as well as each school's percentage of student eligibility for the federal free or reduced lunch programs. The list of schools and their percentage of students eligible for the federal lunch programs was obtained from West Virginia Department of Education staffer J. Merritt (personal communication, December 5, 2004). The teachers' names were obtained from the education directory on the West Virginia Department of Education web site (http://wvde.state.wv.us). The schools were separated by SES, using the percentage of students in each school eligible for the federal free and reduced lunch program. Schools with at least $50 \%$ of the student population eligible for the program were considered low SES, and schools with less than $50 \%$ were considered high SES. This enabled the researcher to investigate the relationship between teacher level of Internet use and the students' socioeconomic status. The schools were divided into three 
broad categories, elementary, middle, and secondary, and for purposes of this study schools were defined as elementary (grades K-5), middle schools (grades 6-8), and secondary (grades 9-12). Each group of schools was divided into two sub-groups, low SES and high SES, yielding a total of six classifications of schools ( 3 categories X 2 sub-groups). The process of selecting the teachers was done using the teacher roster for that school and a random number table.

\section{Procedures}

Initially, fifteen schools, from a list of schools in each school classification group (low SES elementary, high SES elementary, low SES middle, high SES middle, low SES secondary, and high SES secondary) were selected based on a table of random numbers. After the selection of schools, ten teachers at each school were selected to receive the survey instruments. These 900 selected teachers were mailed the CIS instrument described in the next section, and the teachers mailed the surveys back in a prepaid postage envelope that was included with the survey. To track response rates a three digit number was placed on each survey to identify the school's SES classification and name of the teacher. The name of the teacher was only used to determine who did not respond so a second survey could be mailed to encourage their participation twenty days after the first mailing. To improve response rates, teachers who responded were placed in a drawing to win a $\$ 100$ gift card from a large retail store.

To analyze the data effectively, only completed surveys were included. A completed survey was one that had responses for all questions. To promote the best possible analysis of data but maintain feasibility of performing the study at least 61 completed responses from each subgroup were needed. This would give the researcher up to 365 degrees of freedom, which for regression analysis places the $t$ value at the highest mark, infinity, in critical values of $t$ tables. Sixty-one completed surveys in each group of teachers would also allow for each individual 
group of teachers, based on school grade and socioeconomic status, to have a high degree of freedom value if there was a need for any analysis involving just one of the groups. For the groups that did not meet the minimum value of 61 completed responses, other schools and teachers were selected for additional mailings until each subgroup had at least that number of responses.

\section{Instrumentation}

Data were collected from the Classroom Internet Survey (CIS) instrument, which was divided into three sections. The first section provided demographic information about the teacher, the second section provided information regarding classroom Internet use, and the third section provided information on teacher self-efficacy in using the Internet in the classroom. The complete survey instrument is found in Appendix A.

Section one of the instrument consisted of eight demographic questions that define the participant in terms necessary for the independent variables used in the research. This part of the instrument was created by the researcher and contains six multiple choice questions and one question that the participant answered by listing multiple-day Internet-related workshops in which they have participated. The demographic questions asked for the following information:

1. The participants' current teaching assignment by grade level (elementary, middle, or secondary).

2. Number of years teaching experience.

3. Type of computer technical support they receive in school.

4. Amount of in-service $\mathrm{CE}$ credit hours taken on Internet integration.

5. Amount of college credit hours on Internet integration.

6. Number of Internet-accessible computers in their classroom. 
7. The multiple-day professional development workshops taken involving Internet integration.

Part 2 of the instrument was a five point Likert scale survey of teachers' classroom use of the Internet, developed by this researcher. The basis for this part of the CIS instrument was developed by the National Research Center for Career and Technical Education (NCCTE) for a paper titled, "Internet integration in high schools: Patterns, opportunities, and barriers" (Thomas et al., 2002). This section contained 16 questions; with answers ranging from never used to used two to five days per week, and measured the type of classroom Internet use in the teacher's classroom and the frequency of its use. Level of use varied from simple tasks like e-mail or research to higher order processes such as problem solving and inquiry-based learning. The level of use also looked at teacher-directed student Internet activities as a component of teacher level of classroom Internet use. Each teacher had a level of use (LOU) score based on their response to each question in Part 2. The teacher's score ranged from a minimum of 0 (very low) and a maximum score of 64 (very high), and this part of the survey took five to ten minutes to complete. See Appendix B for an illustration on how a teacher's LOU score was tabulated.

Part 3 of the survey instrument was based on the Personal Internet Teaching Efficacy Beliefs Scale (PITEBS), developed and tested for reliability $($ alpha $=.9529)$ and validity by Koul and Rubba (1999). The instrument was modified slightly to fit this study. Part 3 also used a five point Likert scale, measuring the level of self-efficacy in relation to using the Internet in the classroom. Each teacher had a PITEBS score based on their response to each question in Part 3. The minimum score attainable was 13 (Very low) and the maximum was 65 (very high) and this part of the survey took less than five minutes to complete. See Appendix B for an illustration on how a teacher's PITEBS score was calculated. 


\section{Validity and Reliability of the CIS Instrument}

The study's internal validity was reviewed based on considerations outlined by Gay (1987). The study was a one-time survey and not a pre-test/post-test, so outside events or changes due to subject maturation were not a concern. This study dealt with the issue of specificity of variables by including a wide range of teachers from across all grade levels, experiences, and locations. Subjects were randomly selected from schools throughout the state to avoid differential selection of subjects, and due to the large number of potential respondents and the random selection of teachers from across the state, the results could be generalized to the population as a whole. The study ran a slight risk of experimenter effect as the researcher has worked for a federally-funded grant that provided Internet training to K-12 teachers in the state in the years 1996-2000. There were approximately 1,000 teachers who participated in that grant (Hoover, 2003) out of a total of approximately 17,000 teachers in the state (WVDE, 2004) who might have received the survey instrument. The potential for teachers to answer the survey questions in a way they perceive as "correct" was real, and was listed as a limitation of the study.

While the CIS instrument was being used for the first time, parts of the instrument had been used previously. As stated earlier, the Level of Use survey instrument, which was the basis for Part 2 of the CIS instrument, was used by the NCCTE in major study published in 2001, and the PITEBS instrument, which makes up Part 3, has been used in other studies, (Koul \& Rubba, 1999; Watson, in press) as well. As a stand-alone measure, the PITEBS survey instrument was tested for reliability and received an alpha score of .9529 , but the NCCTE study did not report the reliability of their survey instrument. As the merger and adaptation of these two survey instruments created a new instrument (CIS), it was necessary to establish the reliability, content 
validity, and clarity of this instrument. The Cronbach alpha reliability analysis of the CIS instrument yielded a reliability score of .9240 .

To determine the content validity and clarity of the CIS instrument the researcher used a panel of five experts, selected based on background, work experience, familiarity with research in this field, and publications in the fields of self-efficacy, instructional technology, teacher education with technology, and professional development on using the Internet. The panel was selected through personal contact by the researcher and each member was given a copy of the survey instrument questions on a response form. The response form, adapted from Rubio, BergWeger, Tebb, \& Rauch (2003), contained the survey instrument questions as well as the research questions the instrument was to evaluate (See Appendix C for response form). The experts were then asked to rate each item on its clarity and representativeness on a four-point scale, with four being the highest rating, and also provide feedback regarding their ratings. Clarity was defined as the readability of the question and its ability to measure the participant accurately for information being solicited. The representative measure allowed the experts to indicate whether the question would give information regarding the research question for which it was intended.

The results of the panel responses were examined in two ways. First, the responses were analyzed for content reliability, which determines the overall validity and clarity of the instrument. To assess whether an individual survey question is considered reliable the experts' representativeness and clarity scores were grouped separately for each question, with scores of three or four on an item grouped together in each category. The number of responses in the high group is then divided by the total number of responses. If the score was greater than .80 for the representativeness and for the clarity the question was considered reliable. From the analysis all survey questions in the CIS instrument were considered reliable. For the whole instrument, there 
were two methods to assess content reliability, with the more stringent method involving the taking of the total number of survey items determined to be $100 \%$ reliable and dividing by the total number of items on the instrument. The CIS instrument was found to have a reliability of 1.00, which was a perfect score.

To determine the content validity of the CIS instrument the content validity score for each panel member was determined by counting the number of high scores (threes and fours) in the content validity section, then taking that total and dividing by the total number of questions. The score for each member was then averaged together to obtain the overall content validity score, with a score of .80 or higher desired. The CIS instrument received a content validity score of .96.

Table 3.2

CIS Instrument Content Validity Scores by Panel Member

\begin{tabular}{lcccccc}
\hline & Member 1 & Member 2 & Member 3 & Member 4 & Member 5 & Validity average \\
\hline $\begin{array}{l}\text { Content } \\
\text { Validity }\end{array}$ & .97 & .97 & 1.00 & .86 & 1.00 & .96 \\
\hline
\end{tabular}

As stated previously, the panel members could also comment on the survey instrument questions and make suggestions. After completion of the content validity survey the researcher met with each panel member individually to go over their responses and comments, and made revisions to the CIS instrument per those suggestions. One question, "I have the students use the Internet to retrieve information or do research." was determined to be duplicated by the question, "My students use the Internet for research." and so was deleted. In Part 3 of the CIS instrument minor changes to the wording of questions were done to questions $2,9,11,12$, and 13 to improve clarity. 


\section{Data Analysis}

There were ten research questions addressed in this study that were investigated using the CIS instrument. In Table 3.3 each research question is detailed with the corresponding parts of the survey that pertain to it. For each question stepwise multiple regression analysis determined the relationship between the dependent and independent variables. The level of significance to accept or reject each of the hypotheses was $p<.05$.

Table 3.3

Research Questions and Related Survey Questions

\begin{tabular}{lll}
\hline Research Question & Dependent variable & Independent variable \\
& score determined by & determined by \\
\hline What is the relationship between teachers' level & CIS Part 2 & CIS Part 1 \\
of classroom Internet use and the grade level & Score range 0 (low) & Question 1 \\
taught (elementary, middle, high school)? & to 64 (high)
\end{tabular}

What is the relationship between teachers' level

CIS Part 2

CIS Part 1

of classroom Internet use and years of teaching Score range 0 (low) Question 2 experience? to 64 (high)

What is the relationship between teachers' use of CIS Part 2

CIS Part 1

the Internet in the classroom and the level of Score range 0 (low) Question 3 technical support he/she receives at their school? to 64 (high) 


\begin{tabular}{lll}
\hline Table 3.3 (cont.) & Dependent variable & Independent variable \\
Research Question & score determined by & determined by \\
\hline What is the relationship between teachers' level & CIS Part 2 & CIS Part 1 \\
of classroom Internet use and their training on & Score range 0 (low) & Questions 4, 5, and 7 \\
using the Internet in the classroom? & to 64 (high) &
\end{tabular}

What is the relationship between teachers' level

of classroom Internet use and the number of

Internet-accessible computers in the classroom?

\section{CIS Part 2}

Score range 0 (low) Question 6

to 64 (high)

\begin{tabular}{|c|c|c|}
\hline What is the relationship between teachers' level & CIS Part 2 & Data retrieved from \\
\hline of classroom Internet use and school & Score range 0 (low) & WVDE \\
\hline socioeconomic status? & to 64 (high) & \\
\hline What is the relationship between teachers' level & CIS Part 2 & CIS Part 3 \\
\hline of classroom Internet use and teacher Internet & Score range 0 (low) & Score range from 13 \\
\hline self-efficacy? & to 64 (high) & (low) to 65 (high) \\
\hline What is the relationship between teachers' self- & CIS Part 3 & CIS Part 1 \\
\hline efficacy with using the Internet in the classroom & Score range from 13 & Question 2 \\
\hline and years of teaching experie & (low) to 65 (high) & \\
\hline
\end{tabular}


Internet Use 50

\begin{tabular}{|c|c|c|}
\hline Table 3.3 (cont.) & Dependent variable & Independent variable \\
\hline Research Question & score determined by & determined by \\
\hline What is the relationship between teachers' self- & CIS Part 3 & CIS Part 1 \\
\hline efficacy with using the Internet in the classroom & Score range from 13 & Question 3 \\
\hline and the level of technical support received at the & (low) to 65 (high) & \\
\hline teacher's school? & & \\
\hline What is the relationship between teachers' self- & CIS Part 3 & CIS Part 1 \\
\hline efficacy with using the Internet in the classroom & Score range from 13 & Questions 4, 5, and 7 \\
\hline and their Internet-related professional & (low) to 65 (high) & \\
\hline
\end{tabular}




\section{CHAPTER 4}

Findings

The purpose of the study was to determine the factors affecting classroom Internet use and teacher self-efficacy with using the Internet. To that end, the study attempted to answer the following research questions:

1. What is the relationship between teachers' level of classroom Internet use and the following independent variables:
a. grade level taught (elementary, middle, high school)?
b. years of teaching experience?
c. type of technical support received at the teacher's school?
d. Internet-related professional development training?
e. number of Internet-accessible computers in the classroom?
f. socioeconomic status of student population?
g. teacher Internet self-efficacy?

2. What is the relationship between teachers' self-efficacy with using the Internet in the classroom and the following independent variables:
a. years of teaching experience?
b. type of technical support received at the teacher's school?
c. Internet-related professional development training?

This chapter provides a description and an analysis of the data collected, and is divided into three sections. The first section, General Characteristics of the Population, gives the characteristics of the teacher population surveyed. The second section, Findings on Level of Classroom Internet Use, shows the findings regarding the first research question on teacher level 
of classroom Internet use, giving the results for each question in Part 2 of the survey and then detailing the stepwise multiple regression analysis for each independent variable in research question 1. The third section, Findings on Teacher Internet Self-efficacy, gives the findings on the second research question regarding teacher Internet self-efficacy by giving the responses to Part 3 of the Classroom Internet Survey (CIS) instrument and then showing the stepwise multiple regression analysis for each independent variable in research question 2.

The initial set of 900 teachers received the survey instrument at their schools through the U.S. Postal Service during the early spring of 2005. After the initial and follow-up mailing, it was determined that some of the six school sub-groups (elementary low SES, elementary high SES, middle school low SES, middle school high SES, secondary low SES, and secondary high SES) had not returned at least 61 completed responses. For those groups lacking responses mailings were prepared for additional schools and teachers to meet the minimum requirement. In all, 1,036 teachers received the survey instrument, and 419 were returned in a completed format.

\section{General Teacher and School Characteristics}

General data are presented by each of the independent variables to give an overview of the teacher population surveyed. The CIS instrument was sent to 1,036 teachers and 419 were returned in a completed format. Out of the 419 teachers, 129 taught elementary, 153 taught middle school, and 137 taught secondary school. Table 4.1 shows the distribution of responses across six classification groups, representing the number of teachers in each grade level from high and low SES schools. The division of teachers by SES is necessary for the analysis of the independent variable school socioeconomic status for research question 1. 
Data collected from the identification numbers on the returned CIS instrument revealed that of the 419 respondents the largest group of teachers were those with more than 24 years of teaching experience $(n=157)$ followed by those that had 0 to 8 years of teaching experience $(n=$ 114). Table 4.2 gives a complete breakdown of respondents' years of teaching experience.

Table 4.1

Response Frequencies for School Socioeconomic Status Across Grades Taught

\begin{tabular}{cccc}
\hline \multirow{3}{*}{ School SES } & \multicolumn{3}{c}{ Grade taught } \\
\cline { 2 - 4 } & $\begin{array}{c}\text { Elementary } \\
(\mathrm{K}-5)\end{array}$ & $\begin{array}{c}\text { Middle } \\
(6-8)\end{array}$ & $\begin{array}{c}\text { Secondary } \\
(9-12)\end{array}$ \\
\hline Low & 62 & 78 & 68 \\
High & 67 & 75 & 69 \\
\hline
\end{tabular}

Table 4.2

Response Frequencies for Teachers' Years of Teaching Experience

\begin{tabular}{ccc}
\hline Years Experience & $n$ & Percentage of total \\
\hline $0-8$ & 114 & 27.2 \\
$9-16$ & 63 & 15.0 \\
$17-24$ & 85 & 20.3 \\
$24+$ & 157 & 37.5 \\
\hline
\end{tabular}

Teachers were also asked to indicate the type of technical support they receive at their schools. The data showed the most commonly reported type of school technical support was a full-time paid technologist or technology coordinator $(n=132)$. However, combining the results for part-time school technology person $(n=37)$ and teacher or staff as part of their formal job 
responsibilities $(\mathrm{n}=131)$ indicated that part-time in-school support was more prevalent $(\mathrm{n}=$ 168). Table 4.3 gives a complete list of technical support types and their frequencies.

Table 4.3

Response Frequencies for Types of Technical Support

$\begin{array}{lll}\text { Technical Support } & n & \text { Percentage }\end{array}$

\begin{tabular}{lcc}
\hline Full-time, paid school technician or technology & 132 & 31.5 \\
coordinator & 131 & 31.4 \\
Teacher or staff as part of their formal & 101 & 24.1 \\
responsibilities & 37 & 8.8 \\
District or RESA technician & 9 & 2.1 \\
Part-time paid school technology person & 9 & 2.1 \\
Outside contractor or consultant & & \\
Other &
\end{tabular}

Respondents to the survey were asked to identify the number of Internet-accessible computers in their classrooms. From the data collected the most common response for the number of Internet-accessible computers in the classroom was 2-3 $(n=138)$. Forty teachers reported they had more than five computers in their classroom, while 14 indicated that they had none. As grade level increased, the most commonly reported response for number of Internetaccessible classroom computers was a lower value. To illustrate, for elementary teachers the most common response was 4-5 Internet-accessible computers $(n=60)$, for middle school teachers it was 2-3 $(n=62)$, and for secondary teachers it was one computer connected to the 
Internet $(\mathrm{n}=56)$. Table 4.4 shows all responses for the number of Internet-accessible computers for each grade level.

Table 4.4

Response Frequencies for Number of Classroom Internet-accessible Computers by Grade Level Number of computers connected

\begin{tabular}{lcccccc}
\cline { 2 - 5 } \multicolumn{1}{l}{ Grade } & None & 1 & $2-3$ & $4-5$ & $6+$ & $\begin{array}{c}\text { Total } \\
\text { Respondents }\end{array}$ \\
\hline Elementary & 1 & 16 & 48 & 60 & 4 & 129 \\
Middle & 8 & 45 & 62 & 21 & 17 & 153 \\
Secondary & 5 & 56 & 28 & 29 & 19 & 137 \\
$\quad$ Total Respondents & 14 & 117 & 138 & 110 & 40 & 419 \\
\hline
\end{tabular}

When taking a closer look at the number of Internet-accessible classroom computers, there were differences in the quantity per classroom when looking at the SES of the student population. For elementary teachers, $56.4 \%$ of low SES teacher respondents $(n=35)$ indicated they had at least four Internet computers, compared to $43.3 \%$ of high SES elementary teachers (n $=29)$. For middle school teachers, $30.8 \%$ of low SES teachers $(n=24)$ reported at least four Internet computers compared to $18.7 \%$ of high SES teachers $(n=14)$. Secondary teachers in low SES schools indicated that $39.8 \%(n=27)$ had at least four computers as opposed to $30.4 \%$ $(\mathrm{n}=21)$ of high SES secondary teachers. In addition, $55.9 \%(\mathrm{n}=38)$ of secondary teachers in high SES schools indicated they had only one Internet-accessible computer as compared to $26.5 \%(n=18)$ of low SES secondary teachers. Table 4.5 shows the differences between the two classifications of schools separated by grade level. 
Table 4.5

Response Frequencies for Number of Classroom Internet-accessible Computers by Grade level and SES

\begin{tabular}{|c|c|c|c|c|c|c|}
\hline & \multicolumn{5}{|c|}{ Number of computers connected by grade level } & \multirow[b]{2}{*}{$\begin{array}{c}\text { Total } \\
\text { Responses }\end{array}$} \\
\hline & None & 1 & $2-3$ & $4-5$ & $6+$ & \\
\hline \multicolumn{7}{|c|}{ Elementary $(n=129)$} \\
\hline Low SES & 0 & 7 & 20 & 32 & 3 & 62 \\
\hline High SES & 1 & 9 & 28 & 28 & 1 & 67 \\
\hline \multicolumn{7}{|c|}{ Middle $(\mathrm{n}=153)$} \\
\hline Low SES & 3 & 19 & 32 & 11 & 13 & 78 \\
\hline High SES & 5 & 26 & 30 & 10 & 4 & 75 \\
\hline \multicolumn{7}{|c|}{ Secondary $(\mathrm{n}=137)$} \\
\hline Low SES & 4 & 18 & 19 & 19 & 8 & 68 \\
\hline High SES & 1 & 38 & 9 & 10 & 11 & 69 \\
\hline
\end{tabular}

Survey respondents also detailed the professional development and education courses involving Internet integration in which they have participated. Professional development was determined by self-reporting in-service Continuing Education (CE) credits on integrating the Internet, the hours of college credits completed in courses that included lessons on classroom Internet integration, and the number of multiple-day training workshops completed that contained training on classroom Internet integration. Continuing education credits are measured 
in contact hours of instruction, college credits were measured as credit hours completed, and multiple-day workshops were measured by the number of workshops in which they participated.

In terms of Internet training, the data showed that many teachers had little or no inservice CE training, college credits, or multiple-day workshops on integrating the Internet into the classroom environment. In terms of in-service CE training, $58.9 \%(n=247)$ of teachers indicated that they had received six or less hours of training on Internet integration. Table 4.6 shows CE training amounts for all teachers. In terms of college credits obtained, $57 \%(\mathrm{n}=239)$ of teachers reported they had taken three or less hours of college courses, and Table 4.7 shows the breakdown of teachers and college credit hours obtained. For multiple-day training workshops the study results indicated that $54.9 \%(\mathrm{n}=187)$ had not participated in any workshops of this type. The complete listing of teachers and the number of workshops attended is found in Table 4.8 .

Table 4.6

Response Frequencies for Internet Professional Development CE Credits

\begin{tabular}{ccc}
\hline CE credits & $n$ & Percentage \\
\hline $0-6$ & 247 & 58.9 \\
$7-12$ & 82 & 19.6 \\
$13-18$ & 34 & 8.1 \\
$18+$ & 56 & 13.4 \\
\hline
\end{tabular}

When looking at the demographic statistics of the sample population there were differences in the number of Internet connections in the classroom when looking at factors such as SES level and grade level. Those who taught in low SES schools had a tendency to have more 
Internet-accessible computers that those in high SES schools. Elementary teachers' survey responses indicated a higher number of classrooms with four or more computers than middle or secondary teachers' data. Also, a higher number of teachers indicated in their responses that they had little or no training on using the Internet in the classroom than those that had.

Table 4.7

Response Frequencies for College Credit Hours with Internet Integration

\begin{tabular}{ccc}
\hline College credit hours & $n$ & Percentage \\
\hline $0-3$ & 239 & 57.0 \\
$4-6$ & 84 & 20.0 \\
$7-9$ & 32 & 7.6 \\
$10-12$ & 26 & 6.3 \\
$13+$ & 38 & 9.1 \\
\hline
\end{tabular}

Table 4.8

Response Frequencies for Participation in Multiple-day Workshops

\begin{tabular}{ccc}
\hline Multi-day workshops & $n$ & Percentage \\
\hline None & 230 & 54.9 \\
1 & 91 & 21.7 \\
2 & 51 & 12.1 \\
3 & 25 & 6.0 \\
$4+$ & 22 & 5.3 \\
\hline
\end{tabular}




\section{Findings on Level of Classroom Internet Use}

In this section the findings for Part 2 of the CIS instrument and each independent variable of research question 1 are given. The order and structure of this section will be to first discuss the part of the survey instrument and the questions asked that dealt with classroom level of Internet use, then the response distribution for each question, and finally look at the statistical analysis of each independent variable for research question 1 and whether the related hypothesis was accepted or rejected. The response frequency for each of the questions is given in Table 4.9, followed by the analysis of each independent variable discussed separately thereafter. The analysis of each independent variable involved using stepwise multiple regression to determine variable significance.

Part 2 of the survey instrument contained a battery of questions that examined the type and frequency of Internet use occurring in the classroom (see Appendix A), and targeted both individual use by the teacher and teacher-directed student Internet use in the classroom. Questions regarding level of use included such things as student use of the Internet for research, experiments, tutorials, as well as teacher use of web quests, computer-mediated communication, and use of the Internet for research.

The data revealed that teachers and students used the Internet in many ways. Of the 419 teachers responding, $92.6 \%(\mathrm{n}=388)$ used the Internet for lesson planning and information retrieval, while $76.6 \%(\mathrm{n}=321)$ indicated they used it for communicating with other teachers and $71.3 \%(n=299)$ had used it to communicate with non-teachers to help in their teaching. The data also revealed that $89 \%$ of teachers $(n=373)$ had their students use the Internet in the classroom. The most frequent type of student use $(84.7 \%)$ was for research $(n=355)$. 
The survey also showed that certain types of Internet usage were not occurring in the respondents' classrooms. A $59.9 \%(n=251)$ of teachers answered they had never used the Internet to communicate with parents and $69.9 \%(\mathrm{n}=293)$ had never communicated with students outside of class. The results also showed that teachers are not directing students to use it for higher order thinking skills like web quests, simulations, or experiments. For web quests, $51.3 \%$ of teachers $(n=215)$ are not using it with students, while $60.9 \%$ of teachers $(n=255)$ are not having students use the Internet for simulations and experiments. The complete survey results are in Table 4.9.

Table 4.9

Survey Response Frequencies for Level of Classroom Internet Use

\section{Responses}

\begin{tabular}{|c|c|c|c|c|c|c|}
\hline Survey Question & Never & $\begin{array}{l}\text { Less } \\
\text { than } \\
\text { once a } \\
\text { month }\end{array}$ & $\begin{array}{l}\text { 1-3 days } \\
\text { a month }\end{array}$ & $\begin{array}{c}\text { Once a } \\
\text { week }\end{array}$ & $\begin{array}{c}\text { 2-5 days } \\
\text { a week }\end{array}$ & $\begin{array}{l}\text { Total } \\
\text { Usage }\end{array}$ \\
\hline \multicolumn{7}{|l|}{ 1. I use the Internet as a } \\
\hline $\begin{array}{l}\text { resource for my lesson planning } \\
\text { and information retrieval. }\end{array}$ & 31 & 87 & 124 & 82 & 95 & 388 \\
\hline \multicolumn{7}{|l|}{ 2. I use the Internet to share } \\
\hline files and documents with others. & 128 & 102 & 80 & 48 & 61 & 291 \\
\hline \multicolumn{7}{|l|}{ 3. I use the Internet for web } \\
\hline page development and main. & 285 & 72 & 23 & 22 & 17 & 134 \\
\hline
\end{tabular}




\begin{tabular}{|c|c|c|c|c|c|c|}
\hline \multirow[t]{2}{*}{ Table 4.9 (cont.) } & \multicolumn{6}{|c|}{ Responses } \\
\hline & Never & $\begin{array}{c}\text { Less than } \\
\text { once a } \\
\text { month }\end{array}$ & $\begin{array}{l}\text { 1-3 days } \\
\text { a month }\end{array}$ & $\begin{array}{c}\text { Once a } \\
\text { week }\end{array}$ & $\begin{array}{c}2-5 \\
\text { days a } \\
\text { week }\end{array}$ & $\begin{array}{l}\text { Total } \\
\text { Usage }\end{array}$ \\
\hline
\end{tabular}

4. I use the Internet to

communicate with other

teachers.

98

92

74

43

112

321

5. I use the Internet to

communicate with students.

293

63

28

14

$21 \quad 126$

6. I use the Internet to

communicate with parents.

251

74

45

27

$22 \quad 168$

7. I use the Internet to

communicate with others who

may help in my teaching.

120

139

99

38

$23 \quad 299$

8. I use the inquiry-based

lessons that involve the Internet. 107

172

100

23

17

312

9. I use web quests in my

teaching.

215

128

61

10

$5 \quad 204$

10. My students access the

Internet.

46

98

136

53

$86 \quad 373$ 
Table 4.9 (cont.)

Responses

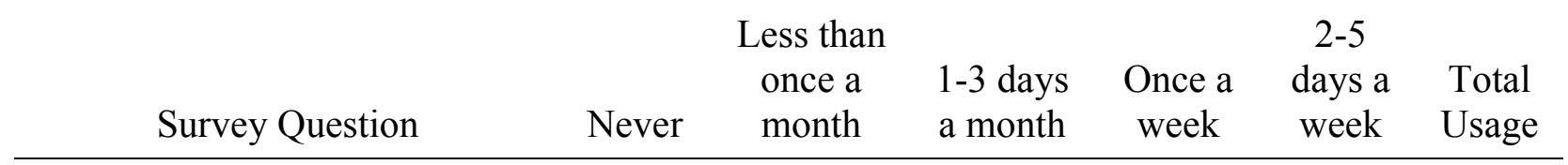

11. My students communicate

with experts, other teaching

professionals, or other people as

part of their class work.

273

100

24

8

14

146

12. My students use the

Internet to help in creating

projects and solving problems.

101

133

133

33

$19 \quad 318$

13. My students use the

Internet for research.

64

148

134

48

25

355

14. My students use the

Internet to find tutorials or to

practice skills.

$118 \quad 12$

124

94

40

43

301

15. My students use the

Internet for web page creation

and maintenance.

367

33

11

5

3

52

16. My students use the

Internet to work with

simulations or experiments.

255

118

33

9

4

164 
The independent variables concerning classroom Internet use involved the factors of grade level taught, years of teaching experience, type of technical support, professional development (in-service $\mathrm{CE}$ credits, college credit hours, and multiple-day workshops), number of classroom computers connected to the Internet, school SES status, and teacher Internet selfefficacy. Part 2 of the CIS instrument contained a battery of 16 questions regarding teacher classroom Internet use and teacher-directed student classroom Internet use. For each question the five possible responses were given a point value from $0-4$, with an answer of "Never" receiving a value of 0 , "Less than once a month", receiving a value of 1, "1-3 days a month" receiving a value of 2 , "Once a week" receiving a value of 3 , and "2-5 days a week" receiving a value of 4 . The point values were summed to get an overall LOU score for that teacher, with a possible range of 0 (low) to 64 (high). Appendix B gives an example of how the teacher LOU score was tabulated. Teacher LOU scores were then grouped according to the independent variable and each group of scores was averaged to get mean LOU scores for the stepwise multiple regression analysis. Stepwise multiple regression was used to allow each variable to be regressed in a manner in which the effects of the other variables were removed. Using stepwise multiple regression allows each independent variable with a probability of $\mathrm{F}$ less than or equal to .05 to be entered into the regression equation separately. This prevents non-significant variables from otherwise affecting the regression analysis findings of the significant variables (See Table 4.10).

The research analysis indicated that 4 of the 7 variables were highly significant predictors $(\mathrm{p}<.01)$ of classroom Internet use: grade level taught, the number of Internet-accessible computers in the classroom, school socioeconomic status, and teacher classroom Internet selfefficacy. The three independent variables found to have no significance $(\mathrm{p}>.05)$ in predicting 
classroom Internet use were teachers' years of teaching experience, type of technical support received, and professional development on integrating the Internet in the classroom. Table 4.10 shows the significant predictor variables and their stepwise multiple regression scores in order from highest to lowest significance. Because stepwise multiple regression does not include variables with a high probability of $\mathrm{F}$ value (those with a probability greater than .05 ), the professional development sub-type college credit hours, was removed from the regression equation, along with years of teaching experience and type of technical support.

Table 4.10

Summary of Stepwise Regression Analysis of Variables Predicting Teacher Level of Internet Use in the Classroom*

\begin{tabular}{lccccc}
\hline \multicolumn{1}{c}{ Variable } & $B$ & $S E B$ & $\beta$ & $t$ & Sig. \\
\hline Personal Internet self-efficacy score & .550 & .046 & .479 & 11.908 & .000 \\
Workshops attended & 2.931 & .832 & .138 & 3.522 & .000 \\
Internet-accessible computers & 2.014 & .398 & .194 & 5.060 & .000 \\
SES & 2.553 & .777 & .120 & 3.286 & .001 \\
In-service credits on Internet integration & 1.046 & .390 & .106 & 2.683 & .008 \\
Grade taught & 1.281 & .497 & .096 & 2.579 & .010 \\
College credit courses & NA & NA & .044 & 1.082 & .280 \\
Teaching experience & NA & NA & .021 & .538 & .591 \\
Technical support type & NA & NA & -.004 & -.096 & .923 \\
\hline$* \mathrm{R}^{2}=.460, \Delta \mathrm{R}^{2}=.009$ & & & & & \\
\end{tabular}

$* \mathrm{R}^{2}=.460, \Delta \mathrm{R}^{2}=.009$ 


\section{Grade Taught and Level of Classroom Internet Use}

Research question 1.a, "What is the relationship between teachers' level of classroom Internet use and the grade level taught (elementary, middle, high school)?" was an effort to determine if grade level predicts classroom Internet use. The results of the data show the range of mean LOU scores was 16.92 to 20.62 , a difference of 3.70 , and the level of Internet use increased as the grade level increased. Table 4.11 outlines the results of this question in terms of mean LOU by grade level. The stepwise multiple regression analysis found a highly significant relationship between the independent variable grade taught and the level of classroom Internet use $(\mathrm{p}<.01)$. The data supported hypothesis $1 . \mathrm{a}$, which stated that secondary teachers have a higher level of classroom Internet use than middle school teachers, who have a higher level of classroom Internet use than elementary teachers. Therefore, hypothesis 1.a was accepted. Table 4.11

Mean Level of Use Scores Based on Grade Level Taught

\begin{tabular}{lrrr}
\hline Grade taught & $M$ & $n$ & $S D$ \\
\hline Elementary (K-5) & 16.92 & 129 & 10.603 \\
Middle (6-8) & 18.82 & 153 & 9.996 \\
Secondary (9-12) & 20.62 & 137 & 11.035 \\
\hline
\end{tabular}

Years of Teaching Experience and Level of Classroom Internet Use

Research question 1.b, "What is the relationship between teachers' level of classroom Internet use and years of teaching experience?" was an effort to understand the link that classroom experience plays a role in how teachers use the Internet. The results of the data show the range of LOU mean scores was 17.96 to 20.57, a small difference between groups of 2.61 . 
Table 4.12 shows the mean LOU score for each category of teaching experience. The stepwise multiple regression analysis showed that teaching experience was not a predictor of classroom Internet use, with $p>.05$. The data did not support hypothesis $1 . b$, which stated that higher years of teaching experience yields higher teacher level of classroom use, and therefore hypothesis $1 . b$ was rejected.

Table 4.12

Mean Level of Classroom Internet Use Based on Years of Teaching Experience

\begin{tabular}{lccc}
\hline Teaching experience & $M$ & $n$ & $S D$ \\
\hline 0-8 years & 17.96 & 114 & 8.719 \\
9-16 years & 20.57 & 63 & 11.424 \\
16-24 years & 19.02 & 85 & 10.574 \\
25+ years & 18.64 & 157 & 11.515 \\
\hline
\end{tabular}

Technical Support and Level of Classroom Internet Usage

Research question 1.c, "What is the relationship between teachers' use of the Internet in the classroom and the type of technical support they receive at their school?" was an effort to determine if technical support plays a role in classroom Internet use. The results of the data show the range of mean LOU scores was 17.33 to 19.81 , a small difference of 2.48 . Table 4.13 shows the mean LOU score for each of the types of technical support. The stepwise multiple regression analysis showed that teaching experience was not a predictor of classroom Internet use, having $p>.05$. The data did not support hypothesis 1.c, which stated that teachers who have full-time technical support will have higher levels of classroom Internet use than teachers who do not. Therefore, hypothesis 1.c was rejected. 
Table 4.13

Mean Level of Classroom Internet Use Based on Type of Technical Support Received

\begin{tabular}{lccc}
\hline Problems fixed by & $M$ & $n$ & $S D$ \\
\hline Full-time school technologist & 19.20 & 132 & 10.368 \\
Teacher or staff as part of their duties & 18.79 & 131 & 10.925 \\
District or RESA technician & 18.24 & 101 & 10.281 \\
Part-time school tech support person & 19.81 & 37 & 12.083 \\
Outside contractor & 17.33 & 9 & 7.583 \\
Other & 17.89 & 9 & 11.418 \\
\hline
\end{tabular}

Professional Development and Level of Classroom Internet Use

Research question 1.d, "What is the relationship between teachers' level of classroom Internet use and professional development training on using the Internet?" was an effort to study the link between teacher training and teacher level of classroom Internet use. Professional development in this study was broken into three categories to better represent the types of development opportunities typically available to teachers. The categories of development were in-service continuing education (CE) training, college credits earned, and multiple-day training workshops. CE training represented opportunities available through school district seminars and training sessions. College credits earned were courses available through colleges and universities, and multiple-day workshops were in-depth programs and initiatives from local, state, or federal programs.

The results of the data for the four classifications of in-service CE credits obtained (0-6, $7-12,13-18,18+$ ) show that the range of mean LOU scores was from 16.07 to 25.38 , a difference 
of 9.31. Table 4.14 displays the mean, number of teachers, and standard deviation of LOU scores for each group. The stepwise multiple regression showed a highly significant relationship $(\mathrm{p}<.01)$ between the number of CE credits and LOU score of classroom Internet use, and the positive Beta value (.106) indicated that as the number of CE credits increased, so did the LOU score.

Table 4.14

Mean Level of Internet Use Score Based on CE Credits

\begin{tabular}{cccc}
\hline CE credits & $M$ & $N$ & $S D$ \\
\hline $0-6$ & 16.07 & 247 & 9.571 \\
$7-12$ & 20.20 & 82 & 10.947 \\
$13-18$ & 25.38 & 34 & 10.592 \\
$18+$ & 24.96 & 56 & 10.002 \\
\hline
\end{tabular}

The results of the data showed that, for college credit courses, the range of mean LOU scores was 16.15 to 26.19 , a difference of 10.05 . Table 4.15 displays the mean, number of teachers, and standard deviation of LOU scores for each group based on the number of college credits earned. The stepwise multiple regression analysis of the variable indicated no significant connection $(p>.05)$ with level of Internet use.

The results of the data show that, for multiple-day training workshops, the range of mean LOU scores was 15.31 to 28.55 , a difference of 13.24 , with the level of classroom Internet use increasing as the number of workshop attended increased. Table 4.16 outlines the results of this question in terms of mean LOU by number of workshops. The stepwise multiple regression 
analysis found a highly significant relationship $(\mathrm{p}<.01)$ between this variable and level of classroom Internet use.

Table 4.15

Mean Level of Internet Use Score Based on College Credits Earned

\begin{tabular}{cccc}
\hline College credits & $M$ & $n$ & $S D$ \\
\hline $0-3$ & 16.15 & 239 & 10.078 \\
$4-6$ & 19.93 & 84 & 10.030 \\
$7-9$ & 23.12 & 32 & 10.591 \\
$10-12$ & 26.19 & 26 & 9.269 \\
$13+$ & 24.53 & 38 & 10.200 \\
\hline
\end{tabular}

Table 4.16

Mean Level of Use Score Based on the Number of Multiple-day Workshops Attended

\begin{tabular}{cccc}
\hline Workshops attended & $M$ & $N$ & $S D$ \\
\hline None & 15.31 & 230 & 9.398 \\
1 & 20.91 & 91 & 9.234 \\
2 & 23.24 & 51 & 10.227 \\
3 & 26.00 & 25 & 12.903 \\
$4+$ & 28.55 & 22 & 10.519 \\
\hline
\end{tabular}

For the three types of professional development, CE credits, college credits, and multipleday workshops, two were found to be highly significant, CE credits and multiple-day workshops. The professional development type college credit courses was not found to be a significant 
predictor of classroom Internet use. The data did not support hypothesis 1.d, which stated that for all types of professional development, classroom Internet use increases as teacher training increases, and therefore hypothesis 1.d was rejected.

Number of Internet-accessible Computers in the Classroom and Level of Classroom Internet Use Research question 1.e, "What is the relationship between teachers' level of classroom Internet use and the number of Internet-accessible computers in the classroom?" was concerned with the access to the Internet teachers had in their classrooms. In this study access was defined as the number of Internet-accessible computers in the teachers' classrooms. The results of the study show that the range of mean LOU scores was 13.86 to 28.18 , a difference of 14.32 , and the mean LOU scores increased as the number of computers increased. Table 4.17 shows the mean LOU by the number of Internet-accessible classroom computers. The stepwise multiple regression analysis found that the number of Internet-accessible classroom computers was a highly significant predictor $(\mathrm{p}<.01)$ of teacher level of Internet use. The data did support hypothesis 1.e, which stated that the more Internet-accessible computers are in the classroom, the higher the level of classroom Internet use. Therefore, hypothesis 1.e was accepted.

\section{School Socioeconomic Status and Level of Classroom Internet Use}

Research question 1.f, "What is the relationship between teachers' level of classroom Internet use and school socioeconomic status?" examined whether SES played a significant role in predicting teacher level of classroom Internet use. The results of the data show that the mean LOU score for teachers from low socioeconomic schools was 33.70 and 35.93 for teachers from high socioeconomic schools. The stepwise multiple regression analysis was highly significant ( $\mathrm{p}$ $<.01)$ for this variable, indicating that a high SES school predicts a higher teacher LOU score. The data did support hypothesis 1.f, which stated that teachers in high socioeconomic schools 
have a higher level of Internet use than teachers in low socioeconomic schools. Therefore, hypothesis $1 . f$ was accepted.

Table 4.17

Mean Level of Use Score Based on the Number of Internet-accessible Computers in the Classroom

\begin{tabular}{cccc}
\hline Computers connected & $M$ & $n$ & $S D$ \\
\hline None & 13.86 & 14 & 14.559 \\
1 & 16.63 & 117 & 9.480 \\
$2-3$ & 16.88 & 138 & 9.134 \\
$4-5$ & 20.82 & 110 & 10.102 \\
$6+$ & 28.18 & 40 & 12.349 \\
\hline
\end{tabular}

Teacher Internet Self-efficacy and Level of Classroom Internet Use

Research question 1.g, "What is the relationship between teachers' level of classroom Internet use and teacher Internet self-efficacy?" examined the relationship between teacher confidence with using the Internet and the level of classroom Internet use. Teacher confidence, or self-efficacy, was measured using a composite score based on the individual teacher responses to Part 3 of the CIS instrument. This composite score of Internet self-efficacy, called the PITEBS score, is discussed further in the Findings on Teacher Internet Self-efficacy section, and an example of how the PITEBS score was calculated for each teacher is found in Appendix B.

The results of the data show that the range of mean LOU scores was 6.50 to 32.13 , a difference of 25.63. The mean LOU score increased as the PITEBS score increased, as shown in Table 4.18, and the stepwise multiple regression analysis found that teacher Internet self-efficacy 
was highly significant $(\mathrm{p}<.01)$, indicating that PITEBS score predicts a teacher LOU score. The data did support hypothesis 1.g, which stated that higher levels of self-efficacy yield higher levels of classroom Internet use. Therefore, hypothesis 1.g was accepted.

Table 4.18

Mean Level of Use Score Based on Teacher Internet Self-efficacy Score

\begin{tabular}{cccc}
\hline PITEBS score & $M$ & $n$ & $S D$ \\
\hline $13-19$ & 6.50 & 2 & 7.778 \\
$20-29$ & 7.58 & 12 & 5.680 \\
$30-39$ & 10.45 & 82 & 6.669 \\
$40-49$ & 17.03 & 145 & 7.830 \\
$50-59$ & 23.49 & 146 & 9.413 \\
$60-65$ & 32.13 & 32 & 12.021 \\
\hline
\end{tabular}

Summary of Factors Affecting Classroom Level of Internet Use

The survey results reveal that several factors were predictors of classroom Internet use. Grade level taught, number of Internet-accessible computers in the classroom, student socioeconomic status, and teacher self-efficacy all were factors that can predict teacher use of the Internet. Years of teaching experience and type of technical support did not predict classroom Internet use. Professional development as a whole did not predict Internet use but two of the development types surveyed, in-service CE credit seminars and multiple-day workshops, were predictors of use. The development type college credit courses involving Internet integration was not a significant predictor. 


\section{Findings on Teacher Internet Self-efficacy}

In this section the findings for Part 3 of the CIS instrument and each independent variable of research question 2 are given. The order and structure of this section will be to first discuss this part of the survey instrument and the questions asked that dealt with teacher Internet selfefficacy, then discuss the response frequency distribution for each question, and finally to look at the statistical analysis of each independent variable for research question 2 and whether the related hypothesis was accepted or rejected. The response frequency for each of the questions is given in Table 4.19, followed by the analysis of each independent variable, discussed separately thereafter. The analysis of each independent variable involved using stepwise multiple regression to determine variable significance.

Part 3 of the survey instrument contained 13 questions measuring teacher's feelings and comfort level towards using the Internet in the classroom. Examples of the questions asked included their feelings about how the respondents felt about using the Internet in their teaching, answering students' Internet questions, and whether they feel they were using the technology effectively in the classroom. The five possible answers to each question were, "Strongly Agree", “Agree", "Neutral", "Disagree", and "Strongly Disagree", and the response frequencies for each question can be seen in Table 4.19. Each respondent's answers to the questions were given a value based on whether the response showed a high or low level of self-efficacy. The point values for each response were then added together to get the Personal Internet Teaching Efficacy Beliefs Scale score, which ranged from 13 (low) to 65 (high). Appendix A shows the questions and the point value possible for each type of response and Appendix B gives an example of how a teacher's PITEBS score was calculated. 
Table 4.19

Teacher Responses on Internet Self-efficacy

Responses

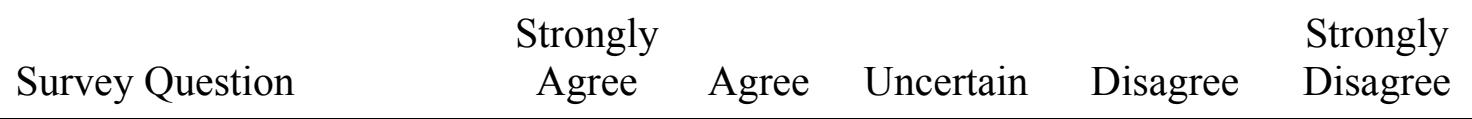

1. I find better ways to teach with the

$\begin{array}{lllll}12 & 60 & 96 & 194 & 57\end{array}$

Internet.

2. I do not teach as well using the

$22 \quad 120 \quad 101 \quad 150 \quad 26$

Internet as I teach using other ways.

3. I know how to teach effectively

$\begin{array}{lllll}15 & 72 & 113 & 181 & 38\end{array}$

using the Internet.

4. I am not very effective in

monitoring activities that involve

14

85

63

205

52

using the Internet.

5. I generally teach ineffectively

when using the Internet.

$\begin{array}{lll}48 & 98 & 220\end{array}$

49

6. I understand how to use the

Internet well enough to be effective

7

53

57

237

65

in teaching with it.

7. I find it difficult to explain to

64

46

243

59

students how the Internet works. 
Internet Use 75

Table 4.19 (cont.)

Responses

\begin{tabular}{|c|c|c|c|c|}
\hline & & & & \\
\hline Survey Question & $\begin{array}{c}\text { Strongly } \\
\text { Agree }\end{array}$ & Uncertain & Disagree & Strongly \\
\hline
\end{tabular}

8. I am typically able to answer

students' Internet questions.

9. I feel I do not have the necessary

skill to teach using the Internet.

$\begin{array}{lllll}12 & 76 & 54 & 200 & 77\end{array}$

10. Given a choice, I would not

invite the principal to evaluate my

teaching when I use the Internet in a

23

95

55

189

57

lesson.

11. When teaching using the

Internet, I am comfortable with

6

43

66

248

56

student questions.

12. I do not know how to interest

4

40

67

249

59

students in using the Internet.

13. When a student has difficulty

understanding how to use the

Internet, I am usually at a loss as to

34

55

248

76

how to help. 
The PITEBS score were then analyzed against the independent variables of professional development training, years of teaching experience, and type of technical support received by the teacher. A stepwise multiple regression analysis was then used to determine which variables were predictors of self-efficacy. The stepwise multiple regression analysis of the data found that 2 of 3 independent variables, professional development and teaching experience, were highly significant predictors $(\mathrm{p}<.01)$ of teacher Internet self-efficacy. Only the independent variable technical support was not a significant predictor. Table 4.20 gives the stepwise multiple regression data for the variables listed from highest significance to lowest.

Table 4.20

Summary of Stepwise Regression Analysis of Variables Predicting Teacher Internet Selfefficacy*

$\begin{array}{llllll}\text { Variable } & B & S E B & \beta & t & \text { Sig. }\end{array}$

Professional development

$\begin{array}{llllll}\text { College credits } & 1.605 & .337 & .227 & 4.756 & .000\end{array}$

$\begin{array}{llllll}\text { Workshops attended } & 3.604 & .838 & .194 & 4.300 & .000\end{array}$

$\begin{array}{llllll}\text { In-service CE credits } \quad 2.058 & .423 & .239 & 4.862 & .000\end{array}$

$\begin{array}{llllll}\text { Teaching experience } & -1.398 & .340 & -.186 & -4.109 & .000\end{array}$

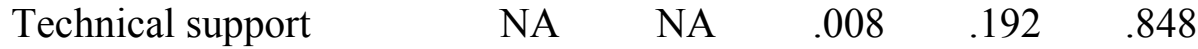

$* \mathrm{R}^{2}=.244, \Delta \mathrm{R}=.030$

Years of Teaching Experience and Teacher Internet Self-efficacy

Research question 2.a, "What is the relationship between teachers' self-efficacy with using the Internet in the classroom and years of teaching experience?" was an examination of how teaching experience affects Internet self-efficacy. The results of the data show the range of 
mean PITEBS scores was from 44.88 to 47.80 , with the mean dropping as the years of teaching experience increased. Table 4.21 shows the results of this question in terms of the mean PITEBS scores based on the years of teaching experience. The stepwise multiple regression found that teaching experience was a highly significant predictor $(\mathrm{p}<.01)$ of teacher Internet self-efficacy. The data did not support hypothesis 2 .a, which stated that increasing experience gives rise to increasing Internet self-efficacy. Therefore, hypothesis 2.a was rejected.

Table 4.21

Mean PITEBS Score Based on Years of Teaching Experience

\begin{tabular}{lccc}
\hline Teaching experience & $M$ & $n$ & $S D$ \\
\hline 0-8 years & 47.80 & 114 & 7.375 \\
9-16 years & 47.43 & 63 & 8.859 \\
16-24 years & 47.08 & 85 & 9.064 \\
24+ years & 44.88 & 157 & 10.475 \\
\hline
\end{tabular}

\section{Technical Support and Teacher Internet Self-efficacy}

Research question 2.b, "What is the relationship between teachers' self-efficacy with using the Internet in the classroom and the type of technical support received at the teacher's school?" was an effort to examine the role of technical support in relation to teacher Internet selfefficacy. The results of the data show that the range of mean PITEBS scores for the technical support types was 45.84 to 48.22 , a difference of only 2.38 , and the mean PITEBS scores for each type of technical support can be seen in Table 4.22. Teachers with access to a full-time school technology person had a mean PITEBS score of 46.77, which was lower than two other types of support, "Part-time school technical person" (47.62) and "Outside contractor" (48.22). 
The stepwise multiple regression analysis did not find a significant relationship with this independent variable $(\mathrm{p}>.05)$. The data did not support hypothesis $2 . b$, which stated that teachers with access to a full-time school technology person have higher Internet self-efficacy than those that do not. Therefore, hypothesis $2 . b$ was rejected.

Table 4.22

Mean PITEBS Score Based on Type of School Technical Support

\begin{tabular}{lccc}
\hline Problems fixed by & $M$ & $n$ & $S D$ \\
\hline Full-time school technologist & 46.77 & 132 & 7.958 \\
Teacher or staff as part of their duties & 46.29 & 131 & 9.925 \\
District or RESA technician & 45.84 & 101 & 10.215 \\
Part-time school tech person & 47.62 & 37 & 9.136 \\
Outside contractor & 48.22 & 9 & 4.353 \\
Other & 46.89 & 9 & 10.565 \\
\hline
\end{tabular}

Professional Development and Teacher Internet Self-efficacy

Research question 2.c, "What is the relationship between teachers' self-efficacy with using the Internet in the classroom and their Internet-related professional development?" was an effort to study the link between teacher training and teacher Internet self-efficacy. Three types of professional development available to teachers were studied: in-service CE training, college credits, and multiple-day workshops. These categories represent the types of development opportunities typically available to teachers. CE training represented opportunities available through school district seminars and training sessions; college credits earned were courses 
available through colleges and universities; and multiple-day workshops were in-depth programs and initiatives from local, state, or federal programs.

The results of the data for the four classifications of in-service CE credits obtained (0-6, $7-12,13-18,18+$ ) showed that the PITEBS scores had a range of scores from 44.22 to 52.43 , a difference of 8.21. The mean PITEBS scores increased as the number of CE credits increased and Table 4.23 displays the mean, number of teachers, and standard deviation of LOU scores for each group. The stepwise multiple regression showed that the number of in-service training credits was a highly significant predictor $(\mathrm{p}<.01)$ of classroom Internet use.

Table 4.23

Mean PITEBS Score Based on CE Credits Earned

\begin{tabular}{lccc}
\hline CE credits & $M$ & $n$ & $S D$ \\
\hline $0-6$ credits & 44.22 & 247 & 8.944 \\
$7-12$ credits & 47.70 & 82 & 9.375 \\
$13-18$ credits & 50.47 & 34 & 7.157 \\
$18+$ credits & 52.43 & 56 & 7.774 \\
\hline
\end{tabular}

The results of the data for college credits earned for coursework that involved integrating the Internet in the classroom shows that the range of mean PITEBS scores was 43.67 to 53.50, a difference of 9.83. The mean scores increased as the number of college credits earned increased, and Table 4.24 displays the mean, number of teachers, and standard deviation of LOU scores for each group. The stepwise multiple regression analysis showed that college coursework was a highly significant predictor $(\mathrm{p}<.01)$ of teacher Internet self-efficacy.

The results of the data for multiple-day workshops to train teachers on using the Internet showed that the range of mean PITEBS scores was 44.05 to 52.32, a difference of 8.27. The 
mean PITEBS scores increased as the number of multiple-day workshops attended increased, and Table 4.25 shows the mean PITEBS scores for the number of workshops attended, the number of respondents, and the standard deviation. Stepwise multiple regression analysis showed that the number of multiple-day workshops attended was a highly significant predictor ( $p$ $<.01)$ of Internet self-efficacy.

Table 4.24

Mean PITEBS Score Based on College Credits Earned

\begin{tabular}{cccc}
\hline College Credits & $M$ & $n$ & $S D$ \\
\hline 0-3 credits & 43.67 & 239 & 9.635 \\
4-6 credits & 47.87 & 84 & 7.497 \\
7-9 credits & 51.06 & 32 & 7.255 \\
$10-12$ credits & 52.27 & 26 & 5.348 \\
$13+$ credits & 53.50 & 38 & 5.584 \\
\hline
\end{tabular}

Table 4.25

Mean PITEBS Score Based on Multiple-day Workshops Attended

\begin{tabular}{cccc}
\hline Workshops attended & $M$ & $n$ & $S D$ \\
\hline None & 44.05 & 230 & 9.132 \\
1 & 48.22 & 91 & 8.150 \\
2 & 49.55 & 51 & 8.327 \\
3 & 51.48 & 25 & 10.405 \\
$4+$ & 52.32 & 22 & 9.244 \\
\hline
\end{tabular}


For each of the three types of professional development, CE training, college credit courses, and multiple-day training workshops, it was found that all were significant predictors of teacher Internet self-efficacy. The data supported hypothesis $2 . c$, which stated that, as professional development increases, so also does teacher Internet self-efficacy. Therefore, hypothesis $2 . c$ was accepted.

Summary of Factors Affecting Teacher Internet Self-efficacy

The teachers' Internet self-efficacy data yielded highly significant results for 2 of 3 independent variables surveyed. The independent variable "Years of teaching experience" was a negative predictor of Internet self-efficacy, as teachers with more years of teaching experience were less comfortable with using the Internet in the classroom then those with fewer years of service. The independent variable that was not a predictor of Internet self-efficacy was type of classroom technical support available to the teacher. Finally, professional development was a significant predictor of Internet self-efficacy for all three types surveyed (in-service continuing education (CE) training, college credits earned, and multiple-day training workshops) in the study. 


\section{CHAPTER 5}

Conclusions, Implications, and Recommendations

There were two purposes for this study. One purpose was to determine what variables affect level of classroom Internet use, and the second was to determine factors that affect the personal Internet self-efficacy of public school teachers. The independent variables examined for their potential relation to level of classroom use were: grade level taught by the teacher, years of teaching experience, type of technical support available to the teacher, Internet-related professional development training, number of Internet-accessible computers in the classroom, socioeconomic status of student population, and teacher self-efficacy with using the Internet. The independent variables studied for their effect on Internet self-efficacy were: years of teaching experience, type of technical support available to the teacher, and Internet-related professional development training.

The study used quantitative research methods in examining the research questions and testing the hypotheses. The data for the study came from surveys mailed to public school teachers throughout the state of West Virginia during the spring of 2005. In all, 1,036 teachers received the surveys, and 419 completed and returned them. The data from the surveys were compiled and used in a stepwise multiple regression analysis to determine factors that were significant predictors for either level of classroom Internet use or personal Internet self-efficacy of the teacher.

This chapter is divided into three sections. The first section will look at conclusions for research questions 1 and 2, while the second section will discuss the implications findings. Finally, the third section will outline recommendations for increasing classroom Internet use and teacher Internet self-efficacy, as well as recommendations for further study. 


\section{Conclusions}

The study provided insight into how certain factors predict teacher Internet self-efficacy and classroom Internet use. Based on the results presented in Chapter 4, the following conclusions regarding research questions 1 and 2 have emerged from the data.

A restatement of research question 1:

What is the relationship between teachers' level of classroom Internet use and the following independent variables:
a. grade level taught (elementary, middle, high school)?
b. years of teaching experience?
c. type of technical support received at the teacher's school?
d. Internet-related professional development training?
e. number of Internet-accessible computers in the classroom?
f. socioeconomic status of student population?
g. teacher Internet self-efficacy?

A restatement of research question 2:

What is the relationship between teachers' self-efficacy with using the Internet in the classroom and the following independent variables:
a. years of teaching experience?
b. type of technical support received at the teacher's school?
c. Internet-related professional development training?

The data for research question 1 showed that research questions 1.a, 1.e, 1.f, and 1.g had a significant relationship with the level of classroom Internet use. Stepwise multiple regression analysis showed grade level taught, number of Internet-accessible computers in the classroom, 
school socio-economic status (SES), and teacher Internet self-efficacy were positive predictors of classroom Internet level of use. The data for research question 1 showed that research questions 1.b, 1.c, and 1.d were not shown to have a significant relationship with the level of classroom Internet use.

The data for research question 2 showed that research questions 2.a and 2.c had a significant relationship with the level of classroom Internet use. Stepwise multiple regression analysis showed years of teaching experience had a negative relationship with teacher Internet self-efficacy, while professional development had a positive relationship. The data for research question 2 showed that research questions $2 . b$ was not shown to have a significant relationship with the teacher Internet self-efficacy.

\section{Conclusions for Research Question 1}

The first conclusion of the study is that grade level taught plays a significant role in the amount and type of Internet use that happens in the classroom. It appears that older students, those in the middle and secondary grades, are more likely to use the Internet and use it in more of a variety of ways than younger students. This could be due to older students being more capable of using the technology with less instruction or help from the teacher. Also, there may be more reluctance to use the Internet at the elementary level because of students finding adult or otherwise inappropriate web sites.

The second conclusion of the study is that teaching experience does not improve teacher Internet use in the classroom. It appears from the data results that experienced teachers are no more comfortable with the significant changes the Internet can present to classroom teaching than new teachers. Though the differences in the mean Level of Use (LOU) score were small, the highest mean was for teachers having 9-16 years of teaching experience, and that the lowest 
means were for teachers with the least experience. Possibly, this may be due to the minimal training opportunities presented due to being new to the field, or to a reluctance to try new things until they grow professionally and become more comfortable with their teaching role.

The third conclusion of the study is that the type of technical support played no significant role in teacher classroom Internet use. It may be that the quality of support would be more significant to classroom teachers than the type of support available at their schools.

The fourth conclusion of the study is that certain types of teacher training on the Internet and its classroom uses improve teacher Internet level of use more than others. Two types of professional development, in-service CE training and multiple-day workshops, were predictors of teacher Internet use, but not college credit courses. CE training and multiple-day workshops can be specialized to meet a new program or other specific type of classroom use. They are tailored to meet the specific needs of the target audience, where college classes have a wide variety of students from all different professional backgrounds, which makes it very difficult to tailor the teaching to meet individual needs. College credit courses may not be as useful to improving classroom Internet use since college courses are more generalized than the other types studied.

The fifth conclusion of the study is that increasing the number of Internet-accessible computers in the classroom would increase teachers' level of classroom Internet use. More classroom computers allow teachers more freedom in how they use the Internet and increase the number of students who can use the Internet at any one time. The more options for use a teacher has, the more likely they are to use the Internet as part of their classroom instruction.

The sixth conclusion of the study is that student poverty affects teacher willingness or ability to use the Internet. Even though the findings in Chapter 4 indicated that low SES schools 
have more classroom Internet-accessible computers, it is possible that other factors, such as computer age and type of Internet connection in the poorer schools may be barriers to classroom use. It may also be that low SES students typically have less opportunity to use computers outside of school than high SES students, affecting their proficiency and discouraging teacher Internet use.

The seventh conclusion of the study is that teacher Internet self-efficacy is directly related to the level of Internet use in the classroom. It appears from the data that self-efficacy affects teacher willingness or ability to use the Internet. Teachers are less likely to try something new if they are not sure of its outcome. The real or perceived possibility of having problems with the technology discourages its use.

\section{Conclusions for Research Question 2}

The first conclusion of the study from the findings on research question 2 is that teaching experience predicts teacher self-efficacy with using the Internet. One possible explanation for the relationship between experience and Internet use may be the result of a technology divide between young and old teachers, as the Internet has only become available in schools within the last 10-15 years. Older teachers, who have already developed their teaching skills, styles, and strategies for delivering instruction may not be as readily accepting of changes in the classroom as newer teachers, who are still developing their own methods and beliefs about instruction. Also, younger teachers have been immersed in computers all of their lives, while older teachers who did not grow up with computers and Internet technology appear to be more uncomfortable with it. There is one confounding variable to teaching experience, which is teacher age. Years of teaching experience and age are related to the extent that the longer you teach, the older you 
get. However, the study did not request teacher age, so it is not possible to ascertain the effect of age on the relationship between years of teaching experience and teacher level of Internet use.

The second conclusion from the findings on research question 2 is that technical support does not affect how teachers feel about their ability with using the Internet. Their feelings of efficacy would appear to be more intrinsic in nature, and not affected by this outside factor.

The third conclusion from the findings on research question 2 is that teacher training on the Internet and its classroom uses does improve teacher self-efficacy. Professional development opportunities, such as in-service training, multiple-day workshops, and college credit courses, are highly significant predictors of teacher Internet self-efficacy. Unlike the findings on teacher level of Internet use, college credit courses are significant predictors of teacher self-efficacy. This may be due to the general curriculum of a college course, as students typically come from a wide array of backgrounds and experiences. This prevents instructors from exploring in detail one particular Internet teaching strategy or concept. However, learning about Internet integration topics, regardless of delivery method, improves the teacher's knowledge base, and increased knowledge of the topic improves the confidence and comfort level of the teacher.

\section{Implications}

As one might expect, teachers in elementary grades have fewer types of uses for the Internet compared to middle and secondary teachers. While one may argue that younger students require more attention when on the Internet, there are many things that younger students could do. The generally smaller amount and type of Internet use by elementary teachers may suggest they are not fully realizing its benefits.

Another implication of the research is that teaching experience has a negative relationship with Internet self-efficacy. The longer a teacher has been in the classroom, the less comfortable 
he or she is in using the Internet. One reason this may be is that personal computers have only been available for approximately 30 years, and the Internet less than half that time, causing a type of technological generation gap. Teachers who are less than 45 years old have grown up surrounded by computers and have experienced the Internet at a relatively early stage in their careers. Teachers who are older did not experience computers as students and did not learn about the Internet until they were well established in their careers and teaching methods. It is only natural that these teachers would be less comfortable using the Internet, and more resistant to change.

The research did not show that full-time technical support affected level of classroom Internet use or teacher self-efficacy, but there were indications that technical support is seriously lacking at many schools. While the survey did not ask teachers about the quality or timeliness of technical support, several respondents wrote comments complaining about it in the margins of the survey instrument. These teachers complained of computers that did not work and had not worked for an extended period of time, of support personnel that did not respond to messages, and of problems with Internet connectivity. While the classroom level of Internet use and teacher Internet self-efficacy are not affected by the type of technical support, the quality of support may affect how often teachers use the technology.

The results of this study indicate that professional development does play an important role in increasing classroom Internet use and teacher self-efficacy with the Internet. While it has long been maintained that training is vitally important in encouraging teacher change in the use of the Internet, and has been supported by more than one Federal report and initiative (USDOE, 2000, 2002, \& 2004), the findings here statistically reinforce this position. Professional development is a necessary component to improved Internet integration. 
Multiple-day workshops and CE credit seminars were significant predictors of teacher level of use and self-efficacy, but college courses were only significant predictors of selfefficacy. This disparity in results may be due to the nature of college classes, workshops, and seminars. Since college classes reach a wide variety of students, they cannot be designed to promote a single program or type of classroom Internet use, while seminars and workshops can be specific and detailed. Therefore, college classes may not directly change a teacher's day-today classroom teaching, but does help in improving the comfort and confidence of teachers in relation to Internet technology.

The findings on school socioeconomic status were very interesting, since the survey respondents reported that low SES schools had more classroom computers connected to the Internet then high SES schools. While the study did not attempt to assess the quality of Internet connections in terms of computer speed and bandwidth, it is unclear whether less affluent schools have some difficulty accessing the Internet due to additional factors. Examples of some of the factors that may contribute to the difference include older computers and slower Internet connections. In addition, the quantity and quality of technical support may not be at the same level of more affluent schools. The research would indicate that other poverty factors play a role in how teachers are using the Internet.

The study showed that teacher Internet self-efficacy was the single most significant predicting factor in teacher level of Internet use in the classroom. Teachers who are comfortable with the Internet use the Internet more, and in more ways, than those who are not. Teachers who are confident in their ability to use and teach with the Internet will integrate it, while those that are not will avoid it. 


\section{Recommendations}

One recommendation from this study to administrators is to increase efforts at Internet integration in the elementary and middle grades, as these teachers have lower level of Internet use than secondary teachers. While some difference can be explained by the age and skill level of the students there are many ways that teachers in these grades could use the Internet to improve instruction. Efforts to increase training on the Internet in these grades should be explored and emphasized.

The study also sheds light on how teachers could be aided in their attempts to integrate the Internet into their classrooms. A recommendation from the findings would be to plan Internet training initiatives to include more support of the teachers in their classrooms. This should include support within the training community of teachers, such as discussion boards, periodic meetings to exchange information and ideas, and continued support from the training staff after the training. These efforts would help improve teacher confidence and efficacy, a significant predictor of level of Internet use.

Another recommendation for administrators or technology coordinators is that quality technical support should be an important component of plans to integrate the Internet in the classroom. Though the survey did not ask for comments regarding the quality of technical support, many teachers took the time to comment about it by writing in the margins of the survey instrument. Several respondents complained about the length of down time between reporting a problem and when a technician repairs it. Others discussed recurring network or computer issues that go days, weeks, or even months without attempts at resolution. Teachers will not be inclined to accept Internet integration if they are not confident that the technology will work when they need it. 
From a technical standpoint, there are also some recommendations for future research. First, future studies should separate new teachers from those teachers who have been teaching for a few years. Grouping teachers whose experience ranged from never taught before to eight years of teaching experience together discounts the fact that new teachers may be facing different issues with Internet use and Internet self-efficacy. It would be better to have respondents give their years of teaching experience instead of listing categories of experience, to get a better idea of the distribution of the sample. A second recommendation would be to ask for respondents' age, as this would eliminate age as a confounding variable in the data analysis.

Research on teacher use of the Internet should focus on the quality of support received other than repairs to computers and networks. One type of support, integration support, deals with efforts to help teachers find information, lessons, and other materials from the Internet, as well as methods of using it with students. This type of support was not examined in this study, but it may also be a factor in helping teachers to use the Internet effectively in the classroom.

The research data in this study did show that professional development improved teacher use and self-efficacy, but it did not examine specific professional development programs, such as PT3 programs and other initiatives, and their success rates. Since self-efficacy plays an important role in teacher Internet use, further research into different professional development program models and their effects on both improvement in Internet use and self-efficacy would be beneficial. Also, researching types of professional development tools, such as follow-up seminars, on-line support, and promoting communication among students and the instructors of the training would be beneficial. This would help to improve professional development training models and thus classroom Internet use. 
There are also issues that need further research concerning the differences in Internet use and poverty level of the schools. As indicated in Chapter 4 schools with a significant student population eligible for free and reduced lunch programs typically had more Internet-accessible classroom computers than schools that did not. Even with this seeming hardware advantage teachers in poorer schools did not use the Internet to the degree that teachers in more affluent schools did. Besides issues of access and hardware, the question remains about what other factors contribute to the digital divide in level of classroom Internet use that still exists between affluent and less-affluent schools.

Another avenue of possible research is to examine the differences in Internet use and efficacy of teachers in different subject areas. Many federal and state Internet initiatives have focused on just one or two academic disciplines, such as science and mathematics. It would be interesting to research if teachers in some disciplines have more access to professional development training than others, and if different groups of teachers need different styles of training to use the Internet effectively in their classrooms. 


\section{References}

Bandura, A. (1997). Self-efficacy: The exercise of control. New York: W.H. Freeman and Co.

Becker, H. (2000). Access to classroom computers. Communications of the ACM, 43(6), 24-25.

Becker, H. (2001, April). How are teachers using computers in instruction? Paper presented at the Annual Meeting of the American Educational Research Association, Seattle, WA.

Becker, H. and Ravitz, J. (1998). The equity threat of promising innovations: Pioneering Internet-connected schools. Journal of Educational Computing Research, 19(1), 1-26.

Bogdan, R. and Biklen, S. (1998). Qualitative research for education: An introduction to theory and methods. Boston, MA: Allyn \& Bacon.

Busch, T. (1995). Gender differences in self-efficacy and attitudes towards computers. Journal of Educational Computing Research, 12(2), 147-158.

Cannon, J. and Scharman, L. (1996). Influence of a cooperative early field experience on preservice elementary teachers' science self-efficacy. Science Education, 80, 419-436.

Christensen, R. (2003). Effects of technology integration education on the attitudes of teachers and students. Journal of Research on Technology in Education, 34(4), 411-433.

Colley, A. and Comber, C. (2003). Age and gender differences in computer use and attitudes among secondary school students: What has changed? Educational Research, 45(2), $155-$ 165.

Dean, D. (2001, March). Infusing technology in K-12 classrooms: A study of one method used to evaluate the impact of a teacher-focused technology integration program. Paper presented at the annual meeting of the Society for Information Technology and Teacher Education, Orlando, FL. 
Durndell, A. (2002). Computer self-efficacy, computer anxiety, attitudes towards the Internet and reported experience with the Internet. Computers in Human Behavior, 18(5), 521-537.

Durndell, A. and Haag, Z. (2002). Computer self-efficacy, computer anxiety, attitudes towards the Internet and reported experience with the Internet, by gender, in an East European sample. Computers in Human Behavior, 18, 521-535.

Foster, J. (2002, March). Why some African-American youth's selves are driving the digital divide. Paper presented at the annual meeting of the Society for Information Technology and Teacher Education, Nashville, TN.

Garland, V., and Wooten (2002). Bridging the digital divide in public schools. Journal of Educational Technology Systems, 30(2), 115-123.

Gay, L. (1988). Educational Research: Competencies for analysis and application ( $3^{\text {rd }}$. ed.). Columbus, OH: Merrill.

Gibson, S. and Oberg, D. (2004). Visions and realities of Internet use in schools: Canadian perspectives. British Journal of Educational Technology, 35(5), 569-580.

Gonzales, C., Pickett, L., Hupert, N. and Martin, J. (2003). The Regional Educational Technology Assistance Program: Its effects on teaching practices. Journal of Research on Technology in Education, 35(1), 1-18.

Harrison, A., Rainer, R., Hochwarter, W., and Thompson, K. (1997). Testing the self-efficacyperformance linkage of social-cognitive theory. The Journal of Social Psychology, 137(1), 79-87.

Hinson, J., and Daniel, C. (2001, June). Connecting across many divides: Digital, racial, and socioeconomic. Paper presented at the annual meeting of the National Education Computing Conference, Chicago, IL. 
Hoover, M. (2003). Effects of the West Virginia K-12 RuralNet project on elementary school teachers' instructional practices. Unpublished doctoral dissertation, West Virginia University, Morgantown.

International Society for Technology in Education. (2002). National educational technology standards for teachers: Preparing teachers to use technology. Eugene, OR: International Society for Technology in Education.

International Society for Technology in Education. (2004). Curriculum and Content Area standards: NETS for students. Retrieved November 12, 2004, from http://cnets.iste.org/currstands/cstands-netss.html

Koul, R. and Rubba, P. (1999). An analysis of the reliability and validity of personal Internet teaching efficacy beliefs scale. Electronic Journal of Science Education, 4(1).

Leh, A. (2000, March). The impact of the technology course on in-service teachers. Paper presented at the annual meeting of the Society for Information Technology and Teacher Education, San Diego, CA.

Milbraith, Y. and Kinzie, M. (2000). Computer technology training for prospective teachers: Computer attitudes and perceived self-efficacy. Journal of Technology and Teacher Education, 8(4), 373-396.

Mills, B. and Whitacre, B. (2003). Understanding the non-metropolitan-metropolitan digital divide. Growth and Change, 34(2), 219-243.

National Center for Educational Statistics. (2000a). Teacher use of computers and Internet in public schools. Stats in brief. (NCES Publication No. NCES 2000-090). Washington, DC: U.S. Government Printing Office. 
National Center for Educational Statistics. (2000b). Teachers' tools for the $21^{\text {st }}$ century. (NCES Publication No. NCES 2000-102). Washington, DC: U.S. Government Printing Office. National Center for Educational Statistics. (2004a). Internet access in U.S. public schools and classrooms: 1994-2002 (NCES Publication No. NCES 2004-011). Washington, DC: U.S. Government Printing Office.

National Center for Educational Statistics. (2004b). Computers and Internet use by children and adolescents in 2001 (NCES Publication No. NCES 2004-014). Washington, DC: U.S. Government Printing Office.

National Telecommunications and Information Administration. (2002). A nation online: How Americans are expanding their use of the Internet. (NTIA publication no. NTIA 2002-0200). Washington, DC: U.S. Government Printing Office.

Norman, M. (2000). The human side of technology. Educational Digest, 65(7), 45-52.

Norris, C. Sullivan, T., Poirot, J., and Soloway, E. (2003). No access, no use, no impact: Snapshot surveys of educational technology in K-12. Journal of Research on Technology in Education, 36(1), 15-27.

Office of Institutional Research (2000). Digital divide: Gender and race variations of computer use by NVCC students. Northern Virginia Community College, Office of Institutional Research report.

President's Committee of Advisors on Science and Technology, Panel on Educational Technology (1997). Report to the president on the use of technology to strengthen K-12 education in the United States. New York, NY: D.E. Shaw \& Co. 
Ravitz, J. (1998). Conditions that facilitate teachers' Internet use in schools with high Internet connectivity. Preliminary findings. Proceedings of the National Convention of the Association for Educational Communications and Technology, USA, 21, 319-335.

Reed, W., Ervin, J., and Oughton, J. (1995). Computers and elementary education students: A ten-year analysis. Journal of Computing in Education, 27(3), 297-316.

Reehm, S., Long, S., and Dickey, J. (2001, March). A comparison of pre-service, in-service, and non-teacher education majors on technology confidence, ability, and use. Paper presented at the annual meeting of the Society for Information Technology and Teacher Education, Orlando, FL.

Roblyer, M. (2000). The national educational technology standards (NETS): A review of definitions, implications, and strategies for integrating NETS into K-12 curriculum. International Journal of Instructional Media, 27(2), 133-147.

Roblyer, M. (2003). Integrating educational technology into teaching. Columbus, OH: MerrillPrentice Hall.

Ross, E., Ertmer, P., and Johnson, T. (2001). Technology integration and innovative teaching practices: A staff development model for facilitating change. Proceedings of the National Convention of Association for Educational Communications and Technology, USA, 24, 870-882.

Ross, J., Hogaboam-Gray, A., and Hannay, L. (2001). Effects of teacher efficacy on computer skills and computer cognitions of Canadian students in grades K-3. The Elementary School Journal, 102(2), 141-156. 
Rubio, D., Berg-Weger, M., Tebb, S., Lee, E. and Rauch, S. (2003). Objectifying content validity: Conducting a content validity study in social work research. Social Work Research, 27(2), 94-104.

Sfard, A. (1998). One-two metaphors for learning and the dangers of choosing just one. Educational Researcher, 27(2), 4-13.

Skinner, R. (2002). Tracking tech trends. Education Week, 21(35), 53-67.

Sottile, J., Watson, G., and Iddings, W. (1998, March). The relationship of computer anxiety and computer competence among rural K-12 math and science teachers. Paper presented at the annual meeting of the Eastern Educational Research Association, Tampa, FL.

Thomas, R., Adams, M., Meghani, N., and Smith, M. (2002). Internet integration in high schools: Patterns, opportunities, and barriers. St. Paul: National Research Center for Career and Technical Education, University of Minnesota. (National Dissemination Center for Career and Technical Education Research Report No.RR2006)

Todman, J. and Monaghan, E. (1994). Qualitative differences in computer experience, computer anxiety, and students' use of computers: A path model. Computers in Human Behavior, 10(4), 529-539.

Torkzadeh, R., Pflughoefe, K. and Hall, L. (1999). Computer self-efficacy, training effectiveness and user attitudes: An empirical study. Behaviour \& Information Technology, 18(4), 299309.

U.S. Department of Education (1999). Designing effective professional development: Lessons from the Eisenhower program. Washington, DC. Retrieved April 14, 2004, from http://www.ed.gov/inits/teachers/eisenhower/execsum/endnotes.html. 
U.S. Department of Education (2000). Does professional development change teaching practice? Results from a three-year study. Washington, DC. Retrieved April 14, 2004, from http://www.ed.gov/inits/teachers/eisenhower/execsum/endnotes.html

U.S. Department of Education (2002). Archived Educational Technology Goals. Washington, DC. Retrieved October 25, 2004, from http://www.ed.gov/Technology/goals.html.

U.S. Department of Education (2003). Office of Educational Technology (OET): Advanced educational technology initiative. Retrieved October 25, 2004, from http://www.ed.gov/about/offices/list/os/technology/advancedtechinitiative.html.

U.S. Department of Education (2004). Office of Educational Technology (OET). Retrieved October 25, 2004, from http://www.ed.gov/about/offices/list/os/technology/index.html. Universal Service Administrative Company. Cumulative national data - Funding year 2003. retrieved August 10, 2004, from http://www.sl.universalservice.org/funding/y2003/national.asp

Watson, G. (in press). Technology Professional Development: Long-term Effects on Teacher Self-efficacy. Journal of Technology and Teacher Education. 
Internet Use 100

Appendix A

Classroom Internet Survey (CIS) Instrument 


\section{Appendix A}

\section{The Classroom Internet Survey (CIS) instrument}

\section{Part 1. General information}

Please answer the questions by circling the correct response(s).
1. Grade taught:
K-5
6-8
$9-12$

2. Years teaching experience:

$0-8$ years

9-16 years

$16-24$ years

$24+$ years

3. Most school computer problems are fixed by (check the one that best fits):

Full-time, paid school technician or technology coordinator

Teacher or staff as part of their formal responsibilities

District or RESA technician

Part-time, paid school technology person

Outside contractor or consultant

Other

4. Estimate the number of Continuing Education (CE) credits you received on using the Internet in the classroom:

\section{0-6 credits $\quad 7-12$ credits $\quad 13-18$ credits $\quad$ More than 18 credits}

5. Estimate the number of college credit hours you have taken that involved using the Internet in the classroom:

$$
\text { 0-3 hours 4-6 hours 7-9 hours 10-12 hours } 13+\text { hours }
$$

6. How many computers do you have that are connected to the Internet in your classroom?

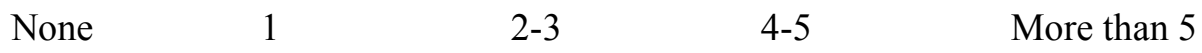

7. List below any multiple-day workshops or programs that you have participated in that involve integrating the Internet in the classroom. Examples: WV K-12 Ruralnet Project, Trek 21, InStep, Phase 9. 


\section{Part 2. Use of the Internet}

For each of the following questions circle the response that most accurately describes how often you use the Internet for the following purposes. Circle only one response.

1. I use the Internet as a resource for my lesson planning and information retrieval.
A) Never
B) Less than once a month
C) 1-3 days a month
D) Once a week
E) 2-5 days a week

2. I use the Internet to share files and documents with others.
A) Never
B) Less than once a month
C) 1-3 days a month
D) Once a week
E) 2-5 days a week

3. I use the Internet for web page development and maintenance.
A) Never
B) Less than once a month
C) 1-3 days a month
D) Once a week
E) 2-5 days a week

4. I use the Internet to communicate with other teachers.
A) Never
B) Less than once a month
C) 1-3 days a month
D) Once a week
E) 2-5 days a week

5. I use the Internet to communicate with students.
A) Never
B) Less than once a month
C) 1-3 days a month
D) Once a week
E) 2-5 days a week

6. I use the Internet to communicate with parents.
A) Never
B) Less than once a month
C) 1-3 days a month
D) Once a week
E) 2-5 days a week

7. I use the Internet to communicate with others who may help in my teaching.
A) Never
B) Less than once a month
C) 1-3 days a month
D) Once a week
E) 2-5 days a week

8. I use inquiry-based lessons that involve the Internet.
A) Never
B) Less than once a month
C) 1-3 days a month
D) Once a week
E) 2-5 days a week 
9. I use web quests in my teaching.
A) Never
B) Less than once a month
C) 1-3 days a month
D) Once a week
E) 2-5 days a week

10. My students access the Internet.
A) Never
B) Less than once a month
C) 1-3 days a month
D) Once a week
E) 2-5 days a week

11. My students communicate with experts, other teaching professionals, or other people as part of their class work.
A) Never
B) Less than once a month
C) 1-3 days a month
D) Once a week
E) 2-5 days a week

12. My students use the Internet to help in creating projects and solving problems.
A) Never
B) Less than once a month
C) 1-3 days a month
D) Once a week
E) 2-5 days a week

13. My students use the Internet for research
A) Never
B) Less than once a month
C) 1-3 days a month
D) Once a week
E) 2-5 days a week

14. My students use the Internet to find tutorials or to practice skills.
A) Never
B) Less than once a month
C) 1-3 days a month
D) Once a week
E) 2-5 days a week

15. My students use the Internet for web page creation and maintenance.
A) Never
B) Less than once a month
C) 1-3 days a month
D) Once a week
E) 2-5 days a week

16. My students use the Internet to work with simulations or experiments.
A) Never
B) Less than once a month
C) 1-3 days a month
D) Once a week
E) 2-5 days a week 
Part 3. Feelings about Internet in the classroom

Circle only one answer for each question. [Note: Numbers in parentheses denote point value that answer receives for statistical analysis purposes. These values were not displayed on the actual survey instrument.]

1. I find better ways to teach with the Internet.
(5)Strongly Agree
(4)Agree
(3)Uncertain
(2)Disagree
(1)Strongly Disagree

2. I do not teach as well using the Internet as I teach using other ways.
(1)Strongly Agree
(2)Agree
(3)Uncertain
(4)Disagree
(5)Strongly Disagree

3. I know how to teach effectively using the Internet.
(5)Strongly Agree
(4)Agree
(3)Uncertain
(2)Disagree
(1)Strongly Disagree

4. I am not very effective in monitoring activities that involve using the Internet.
(1)Strongly Agree
(2)Agree
(3)Uncertain
(4)Disagree
(5)Strongly Disagree

5. I generally teach ineffectively when using the Internet.
(1)Strongly Agree
(2)Agree
(3)Uncertain
(4)Disagree
(5)Strongly Disagree

6. I understand how to use the Internet well enough to be effective in teaching with it.
(5)Strongly Agree
(4)Agree
(3)Uncertain
(2)Disagree
(1)Strongly Disagree

7. I find it difficult to explain to students how the Internet works.
(1)Strongly Agree
(2)Agree
(3)Uncertain
(4)Disagree
(5)Strongly Disagree

8. I am typically able to answer students' Internet questions.
(5)Strongly Agree
(4)Agree
(3)Uncertain
(2)Disagree
(1)Strongly Disagree

9. I feel I do not have the necessary skill to teach using the Internet.
(1)Strongly Agree
(2)Agree
(3)Uncertain
(4)Disagree
(5)Strongly Disagree

10. Given a choice, I would not invite the principal to evaluate my teaching when I use the Internet in a lesson.
(1)Strongly Agree
(2)Agree
(3)Uncertain
(4)Disagree
(5)Strongly Disagree

11. When teaching using the Internet, I am comfortable with student questions.
(5)Strongly Agree
(4)Agree
(3)Uncertain
(2)Disagree
(1)Strongly Disagree

12. I do not know how to interest students in using the Internet.
(1)Strongly Agree
(2)Agree
(3)Uncertain
(4)Disagree
(5)Strongly Disagree

13. When a student has difficulty understanding how to use the Internet, I am usually at a loss as to how to help.
(1)Strongly Agree
(2)Agree
(3)Uncertain
(4)Disagree
(5)Strongly Disagree 
Internet Use 105

Appendix B

Calculating LOU and PITEBS Scores 


\section{Appendix B}

\section{Calculating LOU and PITEBS Scores}

Teacher Level of Use Score

Individual teacher's level of use (LOU) score was determined by giving each of their responses in Part 2 a value based on the frequency of classroom Internet use. Each of the five possible responses were given a point value from 0-4, with an answer of "Never" receiving a value of zero, "Less than once a month", receiving a value of one, "1-3 days a month" receiving a value of 2, "Once a week" receiving a value of 3, and "2-5 days a week" receiving a value of 4. An example LOU score for a teacher:

Table B.1

LOU Values by Sample Teacher Responses for Part 2 Questions

\section{Question Number}

\begin{tabular}{|c|c|c|c|c|c|c|c|c|c|c|c|c|c|c|c|c|c|}
\hline Response & 1 & 2 & 3 & 4 & 5 & 6 & 7 & 8 & 9 & 10 & 11 & 12 & 13 & 14 & 15 & 16 & $\begin{array}{l}\text { Total } \\
\text { pts. }\end{array}$ \\
\hline Never & & 0 & & & & & & & & & 0 & & & & & & 0 \\
\hline $\begin{array}{l}\text { Less than } \\
\text { once a } \\
\text { month }\end{array}$ & 1 & & 1 & 1 & & & & & & & & 1 & & & & & 4 \\
\hline $\begin{array}{l}\text { 1-3 days } \\
\text { a month }\end{array}$ & & & & & & 2 & 2 & 2 & 2 & & & & & & 2 & 2 & 12 \\
\hline $\begin{array}{l}\text { Once a } \\
\text { week }\end{array}$ & & & & & 3 & & & & & 3 & & & & & & & 6 \\
\hline $\begin{array}{l}2-5 \text { days } \\
\text { per week }\end{array}$ & & & & & & & & & & & & & 4 & 4 & & & 8 \\
\hline
\end{tabular}

Total LOU score for sample teacher: $0+4+12+6+8=\mathbf{3 0}$ 
Personal Internet Teacher Efficacy Beliefs Score

For the Personal Internet Teacher Efficacy Beliefs Scale (PITEBS) score each teacher response on Part 3 of the survey instrument was worth 1 to 5 points. The responses for each question were, "Strongly Agree”, “Agree", "Neutral”, "Disagree”, and "Strongly Disagree”. Some questions required disagreement with the statement to show Internet efficacy, and for those questions "Strongly Disagree" was worth five points, "Somewhat Agree" was worth four points, "Neutral" was worth three points, "Somewhat Agree" was worth two points, and "Strongly Agree" was worth one point. For questions that required agreement, the point values were reversed. The point values for each question's responses are found in Appendix A.

Table B.2

PITEBS Values by Sample Teacher Responses and Part 3 Questions

\begin{tabular}{|c|c|c|c|c|c|c|c|c|c|c|c|c|c|c|}
\hline \multirow[b]{2}{*}{ Response } & \multicolumn{13}{|c|}{ Question Number } & \multirow[b]{2}{*}{$\begin{array}{l}\text { Total } \\
\text { pts. }\end{array}$} \\
\hline & 1 & 2 & 3 & 4 & 5 & 6 & 7 & 8 & 9 & 10 & 11 & 12 & 13 & \\
\hline $\begin{array}{l}\text { Strongly } \\
\text { Disagree }\end{array}$ & 5 & & & & & & 1 & & & & 5 & & & 11 \\
\hline Disagree & & & & 2 & & & & 4 & & & & & & 6 \\
\hline Neutral & & 3 & & & & & & & & 3 & & & & 6 \\
\hline Agree & & & 2 & & & & & & 4 & & & 4 & 4 & 14 \\
\hline $\begin{array}{l}\text { Strongly } \\
\text { Agree }\end{array}$ & & & & & 5 & 1 & & & & & & & & 6 \\
\hline
\end{tabular}

Total PITEBS score for sample teacher: $11+6+6+14+6=\mathbf{4 3}$ 
Internet Use 108

Appendix C

Content Validity of Survey 


\section{Appendix C}

\section{Content Validity of Survey}

Name:

INSTRUCTIONS: This measure is designed to evaluate the content validity of the Classroom Internet Survey measure. Please, rate each item as follows:

- Please rate the level of representativeness with respect to the research questions being measured on a scale of $1-4$, with 4 being the most representative. Space is provided for you to comment on the item or suggest revisions.

- Please indicate the level of clarity of each item, also on a four-point scale, with 4 being the highest clarity. Again, please make comments in the space provided.

- Please, evaluate the comprehensiveness of the entire measure by indicating items that should be deleted or added.

- Finally, evaluate the level of clarity of the instructions to the participants, also on a fourpoint scale. Please, make comments in the space provided, and thank you for your time.

Research question \#1 being measured: What degree is a teacher's level of Internet use related to his/her professional development training, years of teaching experience, grade level taught, student socioeconomic status, self-efficacy with using the Internet, and level of technical support available to the teacher?

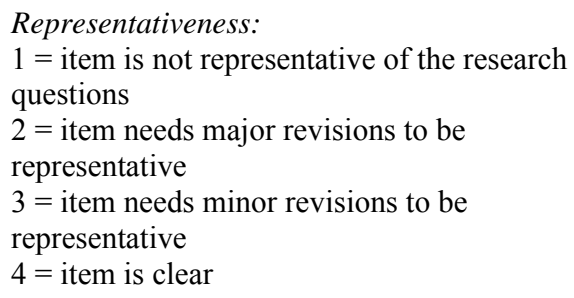

$\underline{\text { Representativeness }}$

Clarity

$\begin{array}{llll}1 & 2 & 3 & 4\end{array}$

Comments:

for my lesson planning and

information retrieval.

I use the Internet to share files and documents with others.

I use the Internet to communicate with other teachers. $\begin{array}{llll}1 & 2 & 3 & 4\end{array}$

Comments:
Items for Research Question 1 $\begin{array}{llll}1 & 2 & 3 & 4\end{array}$

Comments:
Clarity:

$1=$ item is not clear

$2=$ item needs major revisions to be clear

$3=$ item needs minor revisions to be clear $4=$ item is clear $\begin{array}{llll}1 & 2 & 3 & 4\end{array}$

Comments: $\begin{array}{llll}1 & 2 & 3 & 4\end{array}$

Comments:
I use the Internet for web page development and maintenance. $\begin{array}{llll}1 & 2 & 3 & 4\end{array}$

Comments: $\begin{array}{llll}1 & 2 & 3 & 4\end{array}$

Comments: 


\begin{tabular}{|c|c|c|}
\hline Items for Research Question 1 & $\underline{\text { Representativeness }}$ & Clarity \\
\hline $\begin{array}{l}\text { I use the Internet to } \\
\text { communicate with students. }\end{array}$ & 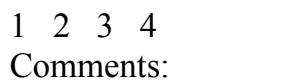 & $\begin{array}{llll}1 & 2 & 3 & 4 \\
\text { Comments }\end{array}$ \\
\hline
\end{tabular}

I use the Internet to

communicate with parents.
1234

Comments:

$\begin{array}{llll}1 & 2 & 3 & 4\end{array}$

Comments:

communicate with others who

may help in my teaching.
I have the students use the Internet to retrieve information or do research. $\begin{array}{llll}1 & 2 & 3 & 4\end{array}$

Comments: $\begin{array}{llll}1 & 2 & 3 & 4\end{array}$

Comments:

$\begin{array}{llll}1 & 2 & 3 & 4\end{array}$

Comments: $\begin{array}{llll}1 & 2 & 3 & 4\end{array}$

Comments:
I use inquiry-based lessons that involve the Internet. $\begin{array}{llll}1 & 2 & 3 & 4\end{array}$

Comments: $\begin{array}{llll}1 & 2 & 3 & 4\end{array}$

Comments:
I use web quests in my teaching. $\begin{array}{llll}1 & 2 & 3 & 4\end{array}$

Comments: $\begin{array}{llll}1 & 2 & 3 & 4\end{array}$

Comments:
My students access the Internet during class. $\begin{array}{llll}1 & 2 & 3 & 4\end{array}$

Comments: $\begin{array}{llll}1 & 2 & 3 & 4\end{array}$

Comments:
My students communicate with experts, other teaching professionals, or other people as part of their class work. $\begin{array}{llll}1 & 2 & 3 & 4\end{array}$

Comments: $\begin{array}{llll}1 & 2 & 3 & 4\end{array}$

Comments: 
Items for Research Question 1 (cont.)

My students use the Internet to help in creating projects and solving problems.

My students use the Internet for $\quad \begin{array}{llll}1 & 2 & 3 & 4\end{array}$ research.

Comments:

My students use the Internet to find tutorials or to practice skills.

$\begin{array}{llll}1 & 2 & 3 & 4\end{array}$

Comments:

My students use the Internet for web page creation and maintenance.

My students use the Internet to work with simulations or experiments.
Clarity

$\begin{array}{llll}1 & 2 & 3 & 4\end{array}$

Comments:

$\begin{array}{llll}1 & 2 & 3 & 4\end{array}$

Comments:

$\begin{array}{llll}1 & 2 & 3 & 4\end{array}$

Comments:

$\begin{array}{llll}1 & 2 & 3 & 4\end{array}$

Comments:

$\begin{array}{llll}1 & 2 & 3 & 4\end{array}$

Comments: 
Research Question \#2

What degree is the teacher's selfefficacy using the Internet-related to Internet-related professional development training received by the teacher, years of teaching experience, and level of technical support available to the teacher?

$\underline{\text { Items for Research Question } 2}$

I am continually finding better ways to teach with the Internet.

Even when I try very hard, I do not teach as well using the Internet as I teach using other ways.

I know how to teach effectively using the Internet.

I am not very effective in monitoring $\quad \begin{array}{llll}1 & 2 & 3 & 4\end{array}$ activities that involve using the Internet.

I generally teach ineffectively when using the Internet.

I understand how to use the Internet well enough to be effective in teaching with it.

I find it difficult to explain to students how the Internet works. $\begin{array}{llll}1 & 2 & 3 & 4\end{array}$

Comments: $\begin{array}{llll}1 & 2 & 3 & 4\end{array}$

Comments: $\begin{array}{llll}1 & 2 & 3 & 4\end{array}$

Comments:
Comments:

$\begin{array}{llll}1 & 2 & 3 & 4\end{array}$

$\begin{array}{llll}1 & 2 & 3 & 4\end{array}$

Comments: $\begin{array}{llll}1 & 2 & 3 & 4\end{array}$

Comments:
Representativeness:

$1=$ item is not representative of the research questions

$2=$ item needs major revisions to be representative

$3=$ item needs minor revisions to be representative

$4=$ item is clear
Clarity:

$1=$ item is not clear

$2=$ item needs major revisions to be clear

$3=$ item needs minor revisions to be clear

$4=$ item is clear $\begin{array}{llll}1 & 2 & 3 & 4\end{array}$

Comments: $\begin{array}{llll}1 & 2 & 3 & 4\end{array}$

Comments: $\begin{array}{llll}1 & 2 & 3 & 4\end{array}$

Comments:

$\begin{array}{llll}1 & 2 & 3 & 4\end{array}$

Comments:

$\begin{array}{llll}1 & 2 & 3 & 4\end{array}$

Comments:

1234

Comments:

$\begin{array}{llll}1 & 2 & 3 & 4\end{array}$

Comments: 
Items for Research Question 2

(cont.)

I am typically able to answer students' Internet questions.
Representativeness

$\begin{array}{llll}1 & 2 & 3 & 4\end{array}$

Comments: $\underline{\text { Clarity }}$

$\begin{array}{llll}1 & 2 & 3 & 4\end{array}$

Comments:
I wonder if I have the necessary skill $\quad \begin{array}{llll}1 & 2 & 3 & 4\end{array}$ to teach using the Internet.
Comments: $\begin{array}{llll}1 & 2 & 3 & 4\end{array}$

Comments:
Given a choice, I would not invite $\quad \begin{array}{llll}1 & 2 & 3 & 4\end{array}$ the principal to evaluate my teaching Comments: when I use the Internet in a lesson.
When teaching using the Internet, I usually welcome student questions. $\begin{array}{llll}1 & 2 & 3 & 4\end{array}$

Comments: $\begin{array}{llll}1 & 2 & 3 & 4\end{array}$

Comments:
I don't know what to do to turn students on to using the Internet. $\begin{array}{llll}1 & 2 & 3 & 4\end{array}$

Comments: $\begin{array}{llll}1 & 2 & 3 & 4\end{array}$

Comments:
When a student has difficulty understanding how to use the Internet, I am usually at a loss as to how to help the student understand it better. $\begin{array}{llll}1 & 2 & 3 & 4\end{array}$

Comments: $\begin{array}{llll}1 & 2 & 3 & 4\end{array}$

Comments: $\begin{array}{llll}1 & 2 & 3 & 4\end{array}$

Comments: 